\title{
The effect of reciprocal connections between demographic decision making and land use on decadal dynamics of population and land-use change
}

\author{
Alexander Zvoleff ${ }^{1}$ and $\underline{\mathrm{Li} \mathrm{An}}^{1}$
}

\begin{abstract}
Although much focus has been given to the study of land use and land cover (LULC) and population change, studies have tended to focus on relationships in a single direction, for instance, the consequences of changing LULC for population processes, or the consequences of changing population dynamics for LULC. Given the highly coupled nature of human-environment systems, we cannot fully understand these systems without considering reciprocal causality, or "feedbacks." This analysis focuses on the Chitwan District of south-central Nepal, a high priority conservation area, and seeks to address the question of how feedbacks between land use and microlevel human decision making impact the decadal time scale dynamics of population and land-use change. It investigates two feedback loops connecting land use and demographic decision making: agricultural land use - marriage timing; and agricultural land use - fertility. Marriage is closely tied to land use in Chitwan because new households in Chitwan are established primarily after marriage. Fertility is connected to land use because of its linkage with population size and future new household formation. However, prior research in Chitwan has shown that residents of agricultural neighborhoods tend to marry earlier, and to have children sooner after marriage. Using an agent-based model, we compare model outcomes from scenarios with and without these feedback loops. Our results indicate that these feedbacks lead to statistically significant differences in population and in land-use outcomes. However, the sizes of these differences are relatively small in magnitude (less than $8 \%$ for the scenarios considered here), even over a 50 -year time scale. These findings are a reminder that CHANS researchers must be careful to consider both effect size and significance when considering the policy implications of model outcomes.
\end{abstract}

Key Words: coupled human-natural system; environment; feedback; fertility; land use; marriage; population

\section{INTRODUCTION}

Although much focus has been given to the study of land use and land cover (LULC) and population change, the regression approaches that are generally used in LULC and population research are limited by their inability to consider reciprocal causality, or "feedbacks" (Zvoleff and An 2014). We define a feedback here as "when a stimulus is fed back to its origin through one or a series of interactions." As anthropogenic influences on most "natural" ecosystems are likely to increase, understanding feedbacks between population and environment is critical to enabling successful management strategies, such as adaptive management (Liu and Taylor 2002, Folke 2006). In other words, not only must we consider how changing LULC affects population, but also how changing population affects LULC.

The emerging coupled human and natural systems (CHANS) framework is one approach to conceptualizing these systems while accounting for feedbacks (Liu et al. 2007, Alberti et al. 2011). The CHANS framework describes human-environment systems as nonlinear complex systems. A challenge of dealing with CHANS is that the processes that determine or affect system dynamics often operate across a range of spatial, temporal, and organizational scales. Given these cross-scale interactions, lags may develop among system responses. Feedbacks between the environment and human systems may affect system dynamics over space and time. Understanding the dynamics of CHANS requires modeling approaches that can incorporate complex couplings between human and environmental change.

There is a growing body of literature exploring CHANS at a range of scales. Acevedo et al. (2008) compared simulation of land-use change in four study sites, two in the United States and two in Venezuela, using a modeling framework allowing feedbacks between land owner's actions and land cover. Le et al. (2012) considered the role of feedbacks and adaptation in moderating land-use transition in Vietnam, finding that the inclusion of alternative ways of representing learning in LULC models can substantially affect model results. The role of feedbacks in slowing or accelerating policy responses to environmental change has also received attention. Horan et al. (2011) examined how feedbacks between social and ecological systems may affect regime shifts, finding that undesirable outcomes can result from management institutions not responding to feedbacks from ecological systems. Jarvis et al. (2012:668) argued that feedback links "need to exist between climate change and societal actions" for policymakers to limit carbon dioxide emissions. Miller et al. (2012) reviewed the literature on feedbacks between conservation actions and social responses, finding that positive feedbacks have thus far been reported more often than negative feedbacks in social-ecological systems. Miller et al. (2012), is in accord with the recent review from Chin et al. (2014:38), which found that more "detailed case studies," using interdisciplinary approaches and integrative methods, are needed to enable researchers to build a general understanding of feedbacks in these systems.

CHANS research draws heavily on the extensive literature connecting population, and LULC change (Lambin et al. 2001, Carr 2004, de Sherbinin et al. 2007). Migration has been shown to play a particularly strong role in the dynamics of CHANS. Research in Latin America has shown that the balance of ruralrural migration (Carr 2009) and rural-urban migration (Aide and Grau 2004) can affect deforestation rates. Barbieri et al. (2005), working in the Northern Ecuadorian Amazon, an area with limited opportunities for agricultural extensification, found population growth can cause fragmentation of land plots, both through "endogenous" demand for land arising from the offspring of previous settlers, and "exogenous" demand from new inmigrants. 
Household-level dynamics also play an important role in CHANS. Research in the Brazilian Amazon has found that the type of smallholder farming system at the household level could be explained in part by household structure (including the size of the household labor force, and number of dependent elderly or children), in addition to distance metrics measuring market access (Walker et al. 2002, Caldas et al. 2007). Working in the Wolong Nature Reserve, in China, Liu et al. (2003) have shown the influence of household demographics on the landscape, showing that changes in the number of persons per household can be an important determinant of habitat degradation due to household activities such as fuelwood collection (Liu et al. 2001, Linderman et al. 2005, Bearer et al. 2008, He et al. 2009). Marriage age, family size preferences, and the time between marriage and the first birth (referred to hereafter as "first birth timing") can also affect land cover change, with a time lag between the first changes in marriage age or fertility patterns, and the first observed changes in landscape-level outcomes (An and Liu 2010).

VanWey (2003) showed that households in Nang Rong, Thailand pursued temporary migration as a form of income diversification, with the size of land holdings affecting the probability of migration differentially for male and female migrants. Barbieri et al. (2009) additionally found that community-level context, including access to road networks, health centers, and schools affects the balance of rural-rural and rural-urban migration. Although road networks were found to increase rural-urban migration, increased road access is also associated with increased off-farm employment opportunities in rural areas. Increased access to health services appeared to reduce out-migration (Barbieri et al. 2009).

Although much has been learned from these studies on the connections between population and environment in CHANS (de Sherbinin et al. 2007), there has been less work to date on the effects of feedbacks between individual-level decision making and the environment in these systems. We do not feel this is due to a lack of recognition in the literature of the important role feedbacks may play in CHANS, but rather due to the limitations of commonly used regression approaches that do not allow direct consideration of reciprocal causation in a single model. The objective of this analysis is to build on the literature by exploring the role of feedbacks between land use and population that act at the individual-level, focusing on a developing rural region bordering a high priority conservation area. We seek to address two key questions regarding feedbacks in the Chitwan Valley CHANS: (1) How are feedbacks between population and land use (focusing on marriage timing and fertility) manifested at the individual-level? (2) What is the dynamic effect of reciprocal connections between land-use change and microlevel human decision making?

In this study we investigate two specific feedback loops connecting land use and demographic decision making. Yabiku (2006a), working in Chitwan, found that changes in community context can influence marriage age. In particular, people living in neighborhoods that are predominantly agricultural tend to marry sooner than those in other neighborhoods, even when controlling for other covariates. Ghimire and Hoelter (2007), and Ghimire and Axinn (2010) also working in Chitwan, found that women in agricultural neighborhoods also tend to have their first child sooner after marriage than those in more urban areas (when controlling for relevant covariates). Rindfuss (1991) showed that activities in the "demographically dense" young adult years, in which individuals experience rapid transitions in family, education, employment, and marital status, are particularly important determinants of lifetime fertility. Because very few births occur in Chitwan outside of marriage, the timing of marriage, and of the first birth after marriage, act as controls on lifetime fertility.

\section{STUDY SITE}

The Chitwan Valley, located in south-central Nepal(Fig. 1), offers an ideal setting for studying feedbacks between population and land use. The area was partially deforested in the 1950s to make way for settlement and agriculture, and the subsequent eradication of malaria in the area was followed by a rapid increase in population (Barber et al. 1997). The population of the western part of the Chitwan District considered here (Chitwan District itself extends to the east outside the study area, see Fig. 1) was approximately 284,939 people as of 2011 (CBS 2012). The valley is part of the lowland Terai landscape at the foothills of the Himalayas, is fairly flat, with a mean elevation of $165 \mathrm{~m}$ in the settled area, and is bordered by rivers to the west and north, and the Chitwan National Park and Barandabar forest (a protected buffer zone forest) to the south and east, respectively. The national park and Barandabar forest are both habitat for endangered species including the Bengal tiger (Panthera tigris tigris) and Onehorned rhinoceros (Rhinoceros unicornis; Carter et al. 2012).

Fig. 1. Overview map of the Chitwan District. CVFS = Chitwan Valley Family Study.

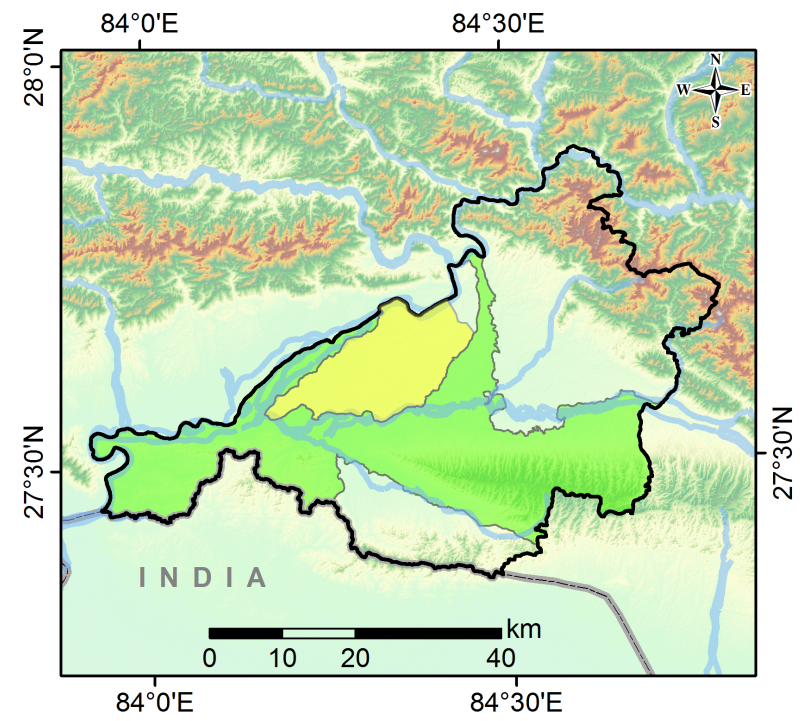

\section{Legend}

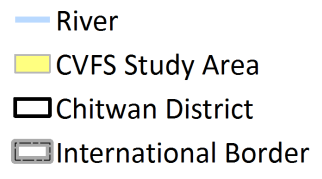

$\square$ National Park and Buffer Zone Elevation $3000 \mathrm{~m}$

$0 \mathrm{~m}$ 
Beginning in 1996, the Chitwan Valley Family Study (CVFS) has tracked land use and demographic data on a sample of the local population of the valley (Axinn et al. 2011). Through continuing longitudinal surveys of 1551 sample households (1551 is the sample size for the original 1996 sample) in 151 sample neighborhoods in Chitwan, the CVFS has gathered neighborhood and individual life-history data from periodic indepth interviews, and monthly follow-up questionnaires. The CVFS also produced detailed maps of LULC (with tape measure and compass) in all sample neighborhoods in 1996, 2001, and 2006.

How to define measures of community context is a continuing discussion in the literature (Zvoleff et al. 2013). Community context is generally defined by constructing neighborhood boundaries, within which measures of land cover, social organizations, or other variables can be defined. The neighborhoods used in the CVFS were defined by the project prior to the beginning of CVFS data collection in 1996 (data collection began in 1997 for the household registry). After determining the settlement boundaries used in the 1991 Nepal Census, the researchers defined the neighborhoods within each settlement through field visits and interviews with residents (Barber et al. 1997). Because the Chitwan Valley is primarily rural, neighborhoods tend to be well defined. Households in the valley are often clustered together, and surrounded by agricultural fields. Irrigation canals and small roads often separate neighborhoods.

Since February 1997, the CVFS has collected monthly records of life events (births, deaths, marriages, and migrations) from the residents of all sample neighborhoods. We use this monthly dataset in conjunction with three detailed household-level interviews focusing on household-level consumption and agriculture conducted in 1996, 2001, and 2006 to parameterize the models in this paper.

\section{METHODS}

To address our two primary research questions on the effect of feedbacks between demographic change and land use within the Chitwan Valley CHANS, we use an agent-based model (ABM). Computer simulations using agent-based models (ABMs) have proven powerful in many disciplines for the study of complex systems (Axtell et al. 2002, Parker et al. 2003, Deadman et al. 2004, An et al. 2005, in press, Brown and Robinson 2006, Entwisle et al. 2008, Evans and Kelley 2008, Walsh et al. 2008, An 2012, Chen et al. 2012, Zvoleff and An 2014). ABM is capable of integrating data from multiple scales, allowing investigation of CHANS while considering feedbacks, heterogeneity, multiple equilibria, and unstable dynamics.

ABMs represent CHANS as a series of interacting components (or agents) at various levels of hierarchical organization. An ABM focusing on LULC change, for example, might represent the actions of, and interactions among, a number of different types of agents, including person agents, household agents (composed of individual person agents), neighborhood agents (composed of household agents), and policy agents (a class representing the combined influence of policymakers). The structure of ABM allows researchers to consider the possibility of emergent phenomena that may arise from lower-level interactions (Liu et al. 2007, Werner and McNamara 2007, Manson et al. 2012).
ABM is useful to CHANS analysts because of its ability to integrate data from multiple spatial, temporal, and/or organizational scales, to include heterogeneous agents, their interactions and resulting emergent phenomena, and to be coupled with cellular models (An et al. 2005, Liu et al. 2007, Werner and McNamara 2007). Rindfuss et al. (2008) argued that given the importance of these individual and household-level decision-making processes in land-use change, ABM is uniquely positioned to enable the generalization of case study findings. Usage of ABM in CHANS research continues to increase rapidly. ABMs have seen much use in LULC change research in particular. Reviews of ABM in CHANS modeling include Parker et al. (2003), focusing on LULC change modeling, and An (2012) on modeling decisions in human-environment systems. Though representation of feedbacks is a commonly cited strength of ABM for CHANS research, few studies have explicitly investigated the effects of feedbacks in CHANS. A recent example is Le et al. (2012), who used an ABM to explore the role of feedback loops between human decision making and land-use change in Vietnam, finding that when adaptation and learning processes are represented in land-use change models, the resultant feedbacks can lead to decadal-scale differences in land-use outcomes.

To extend the literature on feedbacks in CHANS, we use an ABM, the "Chitwan ABM," to explore the decadal time scale dynamics of land use and population change in the Chitwan Valley, while accounting for feedbacks between agricultural land use, marriage timing, and first birth timing. With our modeling work we do not seek to make outright predictions, such as the exact land use composition of the Chitwan Valley at a specific point in the future, but rather to characterize the system dynamics under a range of scenarios, and to better understand the effect of feedbacks between demographic change and land use.

Land-use change within the populated area of Chitwan is occurring primarily because of new building construction (in accordance with our empirical data and field observations at the study site, An et al., in press). Marriage is closely tied to land use in Chitwan because new households in Chitwan are established primarily after marriage (or after in-migration). Fertility is connected to land use because, in the confined area in Chitwan where population cannot expand into the protected areas to the south or east, a larger population size will tend to require more private infrastructure, occupying land that was previously under agriculture.

Given these linkages between population and land use, we hypothesize that loss of agricultural land, holding other factors constant, will lead to delayed marriage, and a delay in the first birth after marriage. This will act as a negative feedback on further conversion of agricultural land to new buildings. We will use the Chitwan ABM to test this hypothesis.

\section{Overview of the Chitwan ABM}

ABMs can be difficult to describe in writing. Given the complexity of ABMs and the many context-specific details that often go into model construction, a standardized description format is helpful to ensure that model descriptions are both "understandable and complete" (Grimm et al. 2010:1). The overview, design concepts, and details (ODD) framework is one approach that has seen increasing usage within the ABM community (Grimm et al. 2006, 2010). ODD provides a structured framework for model 
description that facilitates evaluation of individual models (Grimm et al. 2010), and intercomparison among models (An et al., in press), while also providing sufficient details for other researchers to allow reproduction of results from existing models. For applied research in CHANS, there are several key areas not directly addressed in the original ODD framework: model verification and validation, sensitivity analysis, and uncertainty analysis (An et al., in press, Schmolke et al. 2010). For completeness, we include these components in our ODD description, following the recommendations advocated by An et al. (in press).

For lack of space, we cannot provide a full ODD description of the model here. In the sections that follow, we give an overview of the key details of the Chitwan ABM, focusing on the details relevant to our focus on feedbacks between population and land use. We refer readers to the supplemental materials in Appendix 1 for a complete ODD model description. The model code is available online at http://www.openabm.org/model/3640.

\section{Objectives and key assumptions}

The Chitwan ABM was constructed to explore the role of feedbacks between land use and demographic change in determining decadal scale dynamics of land-use change in the Chitwan Valley. The model is used as a laboratory for testing the relative effects of different drivers of demographic and land use and cover change, and for the exploration of alternative development scenarios.

We represented the population of the western Chitwan Valley using a hierarchical structure of individual people nested within households, nested within their broader neighborhood $(\sim 250 \mathrm{~m}$ radius spatial scale). Consistent with past findings from the literature, we assumed that individual-level decision-making processes regarding fertility, marriage, and migration were shaped by neighborhood characteristics, and that neighborhoods that were close together (in space) were more strongly linked than those that were more distant (people were likely to establish new households nearby their old neighborhoods, for example). Furthermore, and consistent with empirical observations, we assumed that the dominant land-use change in the settled area of the valley was land conversion out of agriculture and into the built environment, and that new household formation was the major driving force behind this change.

\section{Representation of human agents}

The Chitwan ABM simulates a sample of the total population of the western Chitwan study area. The sample used in the Chitwan ABM was taken from the respondents of the CVFS. The 1996 CVFS sample included 1551 households out of the 30,838 households resident in Chitwan as of the 1991 census (CBS 1991). Consistent with past work in Chitwan, the Chitwan ABM excluded 29 households from very rare ethnic groups from consideration because there was an insufficient number of households to establish statistically significant effects for these groups. Therefore, the final household-level sample size for the Chitwan ABM was 1522 households. The CVFS household sample was distributed among 151 neighborhoods spread throughout Chitwan.

The Chitwan ABM represented the population of the Chitwan valley using a multilevel structure mirroring that used in the CVFS (individuals, households, and neighborhoods) as well as the observed social context (electrification, existence of nonfamily organizations or NFOs), and land-use patterns. See Table 1 for an overview of the agent hierarchy in the Chitwan ABM. The lowest-level agent in the model was a "person" agent. The person agent represents a single individual person from the CVFS survey. The model was initialized with 8245 person agents. Each person agent had a number of attributes assigned based on the survey data, e.g., person ID number, age, gender, ethnicity, ID numbers of direct relatives. Each person agent was in turn assigned to one of 1522 households, by matching the household ID number of each individual in the CVFS survey to the appropriate household ID number in the ABM. Each household had a set of attributes assigned from empirical data, e.g., household ID number, whether the household uses any nonwood fuel sources, whether the household owns any land. Household agents were assigned to one of 151 neighborhoods, by linking household and neighborhood ID numbers from the CVFS survey. Neighborhoods, in turn, had a set of attributes, e.g., neighborhood ID number, land use within each neighborhood, distance to the nearest school, distance to the nearest health post, distance to the nearest bus stop, distance to the nearest market, distance to the nearest employer. For complete lists of the attributes assigned to each person, household, and neighborhood agent see Appendix 1 and also the discussion in An et al. (in press).

Table 1. Agents types in the Chitwan agent-based model. "Parent agent" is the agent at the next higher level in the hierarchy.

\begin{tabular}{ccc}
\hline \hline Agent Type & Number of Agents & Parent Agent \\
\hline Person & 8245 & Household \\
Household & 1522 & Neighborhood \\
Neighborhood & 151 & Region \\
Region & 1 & World \\
\hline
\end{tabular}

The 151 neighborhoods in the model acted as a set of "windows" into human-environment interactions within Chitwan. The decision to pursue this type of windowed ABM was made for both theoretical and practical reasons. First, the major purpose of the Chitwan ABM was to explore feedbacks between population and environment, with a heavy focus on community context and individual-level variation. For this purpose, a subset of the data will suffice, the entire population is not required, and accurate representation of individual characteristics and community context is important. Second, because the Chitwan ABM agents were survey based, and were drawn from the population using a systematic sample, if we are interested in the total population of the Chitwan Valley, we can upscale our findings from our sample to the population level simply by applying weighting factors to our results according to the sampling design of the original CVFS survey (see Barber et al. 1997, for details on the CVFS sampling frame). Third, given the longitudinal demographic and socioeconomic data available through the CVFS project, we were hesitant to create agents in our model (using up scaling or resampling), because we might have lost or diluted the interrelationships between the agents and agent state variables in our model. Last, a practical concern was the population size in Chitwan, i.e., 215,000 people in almost 45,000 households by 2001 (CBS 2001), which, given the 
complexity of our model, would slow down the simulation speed considerably, with little benefit, if we were to attempt to incorporate all 215,000 people in the model.

\section{Representation of the landscape}

Agricultural land is the predominant land use category within the cleared area of the study site (occupying greater than $80 \%$ of the total nonforested land area) as of 1996, when the first CVFS mapping was conducted. The CVFS collected land use data at three points in time (1996, 2000, and 2007) at the neighborhoodlevel. Each neighborhood was mapped by hand, with compasses and tape measures. The original survey mapped 18 different classes, for simplicity, and consistency with prior analyses (such as Yabiku 2006a, Axinn and Ghimire 2007, Ghimire and Hoelter 2007); we collapsed these 18 classes into 5 classes: agricultural vegetation, nonagricultural vegetation, private buildings, public buildings, and other (canals, ponds, rivers, silted land, and undeveloped land).

Land-use data were collected at the neighborhood level through the CVFS; individual land parcels were not connected to individual households, because no unique IDs exist in the mapping data to match a household plot with its owner. Given this limitation, the ABM tracks land use at the neighborhood level. Land use within the model was stored as point data, where each point was the centroid of a neighborhood. Each point has a value assigned for the total land area (in hectares) within each of the five land-use classes. Summary statistics on LULC in the neighborhoods included in the Chitwan ABM are listed in Table 2 .

Table 2. Summary statistics of the five land-use classes as mapped in 1996, 2000, and 2007 as a part of the Chitwan Valley Family Study. Listed first in each cell is the land area in hectares (summed across all neighborhoods) within that class. Listed in parentheses is the percentage of total land area in each class. Note that the total changes slightly between years; this is due not to differences in neighborhood size but rather to the margin of error in the neighborhood mapping data.

\begin{tabular}{lccc}
\hline \hline Class & 1996 & 2000 & 2007 \\
\hline Agricultural & $879.9 \mathrm{ha}$ & $875.6 \mathrm{ha}$ & $854.2 \mathrm{ha}$ \\
Vegetation & $(80.0 \%)$ & $(79.4 \%)$ & $(77.6 \%)$ \\
Nonagricultural & $50.2 \mathrm{ha}$ & $35.3 \mathrm{ha}$ & $54.4 \mathrm{ha}$ \\
Vegetation & $(4.6 \%)$ & $(3.2 \%)$ & $(4.9 \%)$ \\
Private Buildings & $82.3 \mathrm{ha}$ & $88.4 \mathrm{ha}$ & $94.4 \mathrm{ha}$ \\
& $(7.5 \%)$ & $(8.0 \%)$ & $(8.6 \%)$ \\
Public Buildings & $59.2 \mathrm{ha}$ & $64.3 \mathrm{ha}$ & $66.9 \mathrm{ha}$ \\
& $(5.4 \%)$ & $(5.8 \%)$ & $(6.1 \%)$ \\
Other & $28.4 \mathrm{ha}$ & $39.5 \mathrm{ha}$ & $31.2 \mathrm{ha}$ \\
& $(2.6 \%)$ & $(3.6 \%)$ & $(2.8 \%)$ \\
Total & $1100.1 \mathrm{ha}$ & $1103.1 \mathrm{ha}$ & $1101 \mathrm{ha}$ \\
& $(100 \%)$ & $(100 \%)$ & $(100 \%)$ \\
\hline
\end{tabular}

\section{Processes in the model}

The Chitwan ABM drew on theory from the literature on the drivers of LULC change, and on the key determinants of demographic change, including past studies conducted in Chitwan. Existing work in Chitwan has shown the influence of land-use change (such as the prevalence of agriculture in an individual's neighborhood) on human behaviors including fertility (Ghimire and Hoelter 2007, Ghimire and Axinn 2010), migration (Massey et al. 2010), and marriage (Yabiku 2006a,b). Drawing on this body of evidence, the Chitwan ABM used separate submodels to model demographic and land-use change, allowing for reciprocal causation, whereby changes in land use can influence human behaviors, which, in turn, determine land use patterns.

The model ran with a monthly time step, beginning in February 1997 (the first month of the CVFS household registry data collection), and ending in December, 2050. A monthly time step was chosen to match the available data from the CVFS and the time scale on which the demographic events that we model operate (see Appendix 2). A series of submodels were run in succession at each time step (Fig. 2). Each time step began with the fertility submodel, which has separate procedures for modeling women's first children after marriage, and for modeling subsequent births to women who have already had their first child. The mortality submodel ran next. The marriage submodel followed, and then the migration submodel, which allowed in- and out-migration at the individual and household levels. The last submodels to run were the divorce submodel and the education submodel. Landscape change due to new household formation was modeled in both the marriage and migration submodels (see Appendix 1 for details).

Fig. 2. Process scheduling in the Chitwan agent-based model.

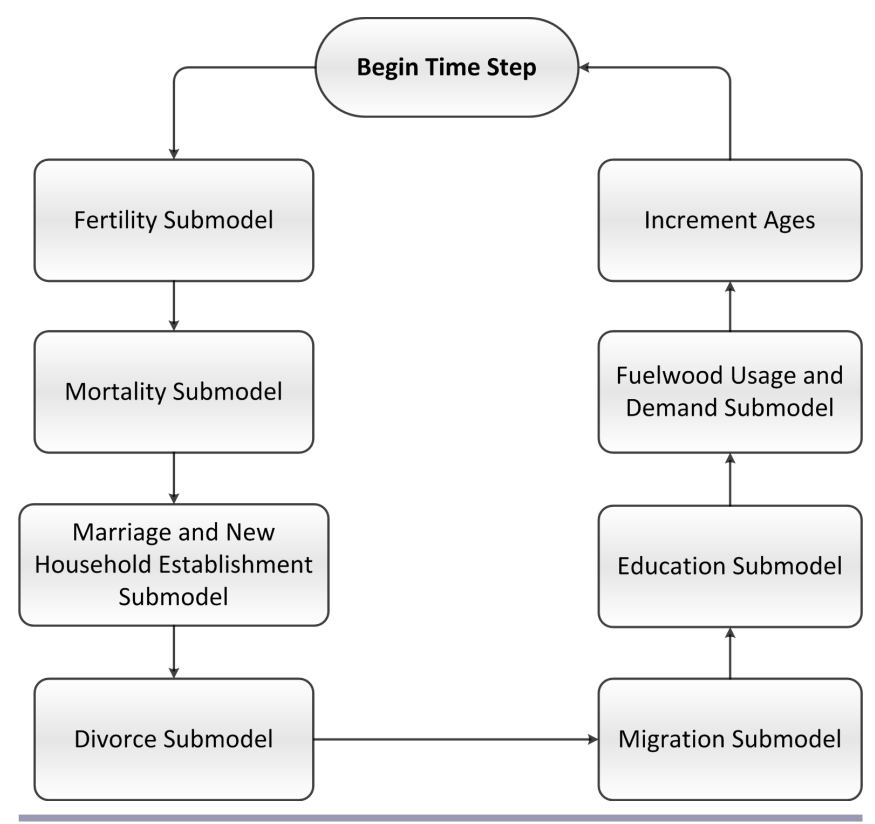

The subset of submodels that apply to a particular person agent in the model during a given time step was determined by that agent's age and, for some submodels, by their marital status, education status (in or out of school), and sex. If during a particular time step an agent did not meet the age, sex, or marital status requirements for a submodel, that agent would not experience that submodel.

To clarify, we can consider a hypothetical person agent to see how they might experience the submodels seen in Figure 2. The 
increment ages and mortality submodels will be experienced by this agent for every time step for their entire life (they will always age, and are always at risk of dying, though the probability of death varies by age and sex), and the fuelwood usage and demand submodel applies to all household agents for all time steps. Other submodels will only apply at particular points during a person agent's life course. The marriage submodel will only apply to unmarried agents after they have reached the minimum marriage age (default of 15 years old). The divorce submodel will only apply to married agents. Male person agents will never experience the fertility submodel. A woman person agent will only experience the fertility submodel after she has married and reached the minimum birth age (default of 15 years old), and it will no longer apply after she reaches her desired number of children or the maximum birth age (default to 45 years). The migration submodel applies to all person agents resident in Chitwan that are older than the minimum age of out-migration (default of 15 years old). The education submodel only applies to agents older than the minimum age to start schooling (6 years old) but below their model-determined final level of education (see Appendix 1 for more details on the education submodel).

\section{Chitwan ABM model details}

To give readers a clearer idea of the structure of the processes and structure of the Chitwan ABM, we describe the initialization of the model, and the primary submodels of importance for our focus in this paper (marriage timing, first birth timing, and landuse change). For additional details, see Appendix 1.

\section{Initialization}

The Chitwan ABM was initialized using household registry and survey data from the CVFS survey. The number of agents of each type followed the distribution of the CVFS data. The initial populations of each of the three primary types of agent (persons, households, and neighborhoods) were determined by the number of respondents in the CVFS survey data. The respondents from the CVFS survey were represented in the model using a one-toone mapping.

\section{Submodels}

Marriage, fertility, mortality, migration, education, and land-use change were modeled based on relationships derived from existing empirical works, and from our analysis of time series data from the CVFS. We focused in detail here on the marriage, fertility, and land-use change submodels because these models were central to our research question in this paper. Additional details on the remaining submodels, including model coefficients, are available in Appendix 1.

The marriage submodel used regression results to parameterize the marriage process based on a number of covariates. Existing work in Chitwan has shown that individuals within primarily agricultural neighborhoods marry sooner than those in primarily urban neighborhoods, even when controlling for other factors (Yabiku 2006a). To represent this in the model, the marriage submodel used regression coefficients derived from a discretetime hazard analysis predicting probability of marriage within a given month (Table 3). The covariates included in the marriage timing model were chosen based on the work of Yabiku (2006a) in investigating the effects of land-use change on marriage timing in Chitwan. See Yabiku (2006a) for more detailed discussion of this model.
The regression model used to represent marriage timing in the Chitwan ABM was rerun for this paper based on the modeling strategy and controls used in Table 2, model 5 in Yabiku (2006a:456), to obtain the intercept for the regression equation, and the values of the monthly dummy variables included in the model to represent the baseline hazard (these parameters were estimated, but not published in Yabiku 2006a). Because different statistical software was used, the regression coefficients presented here vary slightly from those in the original paper, though the significance and effect sizes for the coefficients generally agree.

We converted the regression coefficients to odds ratios (exponentiated regression coefficients) so that they could be more easily interpreted (Table 3 ). An odds ratio greater than one on a covariate therefore meant that an increase in the covariate would lead to a decrease in marriage age (by increasing the monthly probability of marriage). In each time step, the marriage submodel calculates the monthly probability of marriage for each eligible individual based on the values of these covariates during that time step.

Following the work of Yabiku (2006a), the marriage timing regression model included the log of agricultural vegetation as a covariate, to be consistent with theoretical expectations of the feedback of land-use change on marriage timing. The log scale represents, for example, the expectation that the transition from $10 \%$ to $20 \%$ agriculture (a $10 \%$ change) would be expected to have more of an effect on individuals than the transition from, for example $80 \%$ to $90 \%$ agriculture (again a $10 \%$ change). Although the magnitude of both these changes is identical, the relative impact of a doubling of agricultural land use (10\% - 20\%) would represent a greater qualitative change in a neighborhood than going from $80 \%$ - 90\% agriculture.

To address our question of the effects of feedbacks on landscape dynamics, we used two different models of marriage timing in our experiments: (1) the "full model" including a coefficient linking change in agricultural vegetation to marriage timing, and (2) the "reduced model" in which we did not include the agricultural land use covariate. All other covariates were identical between the two models.

To model the marriage process, at the beginning of each time step, a list was made of all unmarried individuals, both male and female. The marriage process in the Chitwan began with the model first running through this list and checking if each person (male or female) had reached the minimum marriage age (15), and was below the maximum marriage age (35, both are empirically determined). For those meeting these requirements, the probability of marriage within that time step was calculated for each individual using whichever of the two marriage models (full or reduced) had been chosen for the model run. Once this probability was calculated, a random number was drawn on the interval of $[0,1]$, and, if the number was less than or equal to the probability of marriage for that individual, the person was added to a list of individuals to be married in that time step. To model in-migration through marriage, individuals may marry an inmigrant with a probability of 0.1 , as calculated from the 48 months of the CVFS household registry data.

Next, males and females within the list were paired up, subject to the requirement that all individuals marry within their own ethnic 
Table 3. Marriage models (following the work of Yabiku 2006a). Odds-ratios are from a discrete-time event history analysis predicting monthly hazard of first marriage. Listed in parentheses are the z-scores for each odds-ratio.

\begin{tabular}{|c|c|c|c|c|c|c|}
\hline & \multicolumn{3}{|c|}{ Full Model } & \multicolumn{3}{|c|}{ Reduced model } \\
\hline & Odds Ratio & $\mathrm{p}$ & Sig. & Odds Ratio & $\mathrm{p}$ & Sig. \\
\hline Percent neighborhood in agriculture (logged) & 1.138 & 0.064 & & & & \\
\hline \multicolumn{7}{|l|}{ Nonfamily organizations (min. by foot) } \\
\hline School & 1.012 & 0.138 & & 1.012 & 0.152 & \\
\hline Health post & 0.999 & 0.711 & & 1.000 & 0.885 & \\
\hline Bus stop & 1.005 & 0.282 & & 1.006 & 0.181 & \\
\hline Market & 0.999 & 0.842 & & 1.000 & 0.902 & \\
\hline Employer & 1.003 & 0.305 & & 1.004 & 0.189 & \\
\hline \multicolumn{7}{|l|}{ Nonfamily activities } \\
\hline Years schooling completed & 0.997 & 0.893 & & 0.995 & 0.798 & \\
\hline Enrolled in school & 0.669 & 0.000 & $* * *$ & 0.679 & 0.001 & $* * *$ \\
\hline \multicolumn{7}{|l|}{ Month } \\
\hline February & 2.904 & 0.000 & $* * *$ & 2.905 & 0.000 & $* * *$ \\
\hline March & 4.847 & 0.000 & $* * *$ & 4.848 & 0.000 & $* * *$ \\
\hline April & 1.430 & 0.253 & & 1.431 & 0.253 & \\
\hline May & 4.603 & 0.000 & $* * *$ & 4.598 & 0.000 & $* * *$ \\
\hline June & 2.261 & 0.004 & $* *$ & 2.259 & 0.004 & $* *$ \\
\hline July & 2.405 & 0.002 & $* *$ & 2.403 & 0.002 & $* *$ \\
\hline August & 0.678 & 0.305 & & 0.679 & 0.305 & \\
\hline September & 0.397 & 0.040 & $*$ & 0.397 & 0.040 & $*$ \\
\hline October & 0.512 & 0.105 & & 0.512 & 0.105 & \\
\hline November & 0.687 & 0.320 & & 0.687 & 0.320 & \\
\hline December & 2.510 & 0.001 & $* *$ & 2.510 & 0.001 & $* *$ \\
\hline Female $^{\dagger}$ & 2.245 & 0.000 & $* * *$ & 2.241 & 0.000 & $* * *$ \\
\hline \multicolumn{7}{|l|}{ Ethnicity ${ }^{\ddagger}$} \\
\hline Lower Caste Hindu & 1.014 & 0.942 & & 1.009 & 0.964 & \\
\hline Newar & 0.786 & 0.229 & & 0.717 & 0.089 & . \\
\hline Hill Tibeto-Burmese & 1.187 & 0.256 & & 1.191 & 0.245 & \\
\hline Terai Tibeto-Burmese & 0.906 & 0.508 & & 0.907 & 0.512 & \\
\hline $\mathrm{Age}^{\S}$ & 0.745 & 0.004 & $* *$ & 0.742 & 0.004 & $* *$ \\
\hline Age-squared ${ }^{\S}$ & -0.014 & 0.018 & $*$ & -0.014 & 0.019 & $*$ \\
\hline Intercept & 0.000 & 0.000 & $* * *$ & 0.000 & 0.000 & $* * *$ \\
\hline Degrees of freedom & \multicolumn{3}{|c|}{42,619} & \multicolumn{3}{|c|}{42,620} \\
\hline Residual deviance & \multicolumn{3}{|c|}{4666.9} & \multicolumn{3}{|c|}{4670.7} \\
\hline AIC & \multicolumn{3}{|c|}{4720.9} & \multicolumn{3}{|c|}{4722.7} \\
\hline \multicolumn{7}{|c|}{$\begin{array}{l}\text { Two sided P-values. Significance is coded as: } \cdot \text { for } \mathrm{P}<0.1,{ }^{*} \text { for } \mathrm{P}<0.05,{ }^{* *} \text { for } \mathrm{P}<0.01,{ }^{* * *} \text { for } \mathrm{P}<0.001 \text {. } \\
\text { 'The odds-ratio for sex is relative to males. } \\
\text { "The odds-ratios for ethnicity are relative to Upper-caste Hindus. } \\
{ }^{\text {T}} \text { For age and age-squared, coefficients are listed rather than odds ratios because for these two covariates odds ratios are not directly interpretable, } \\
\text { for example, age cannot be held constant without varying age-squared. }\end{array}$} \\
\hline
\end{tabular}

group. The empirical data shows that spouses tended to be fairly close in age, with the man tending to be slightly older than the woman. To account for the expected age differential between spouses, we used a multinomial logistic regression predicting spouse age, with sex, age, and ethnicity as the predictors (see Appendix 1).

There were three parts to the fertility model in the Chitwan ABM. First was the determination of a woman's desired family size. Second, a submodel was used to model the first birth after marriage. Third, a separate procedure modeled all subsequent births, up until a woman's desired family size was reached (or until she was no longer married, or died). These models were developed using empirical data from the CVFS household registry, which contains monthly records of live births for all individuals in the survey.

Desired family size was determined based on the desired family size reported in the CVFS data. For new agents born into the model, a desired family size was assigned to each woman at marriage based on a histogram constructed from the reported data (see Appendix 1). Although future work may take into account covariates associated with desired family size, this is not done at present. 
Table 4. Models of first birth timing (following the work of Ghimire and Hoelter 2007, Ghimire and Axinn 2010). Odds-ratios are from a discrete-time event history analysis predicting monthly hazard of first birth. Listed in parentheses are the z-scores for each oddsratio.

\begin{tabular}{|c|c|c|c|c|c|c|}
\hline & \multicolumn{3}{|c|}{ Full Model } & \multicolumn{3}{|c|}{ Reduced Model } \\
\hline & Odds Ratio & $\mathrm{p}$ & Sig. & Odds Ratio & $\mathrm{p}$ & Sig. \\
\hline Percent neighborhood in agriculture & 1.006 & 0.458 & & & & \\
\hline \multicolumn{7}{|l|}{ Community characteristics } \\
\hline Neighborhood area & 0.420 & 0.428 & & 0.286 & 0.194 & \\
\hline Distance to urban center & 1.007 & 0.548 & & 1.007 & 0.550 & \\
\hline Electricity available & 1.298 & 0.105 & & 1.308 & 0.094 & . \\
\hline Nonfamily services within a 15 -min walk & 0.996 & 0.619 & & 0.998 & 0.778 & \\
\hline \multicolumn{7}{|l|}{ Controls } \\
\hline Parents' characteristics & 0.968 & 0.824 & & 0.988 & 0.933 & \\
\hline Mother's number of children & 0.977 & 0.504 & & 0.976 & 0.479 & \\
\hline Mother's education & 0.922 & 0.678 & & 0.939 & 0.743 & \\
\hline Mother's work & 0.930 & 0.686 & & 0.938 & 0.720 & \\
\hline Father's education & 0.874 & 0.324 & & 0.875 & 0.325 & \\
\hline Father's work & 0.721 & 0.021 & $*$ & 0.722 & 0.022 & $*$ \\
\hline \multicolumn{7}{|l|}{ Respondent's ethnicity ${ }^{\dagger}$} \\
\hline Low Caste Hindu & 1.026 & 0.922 & & 1.019 & 0.944 & \\
\hline Hill Tibeto-Burmese & 0.539 & 0.003 & $* *$ & 0.537 & 0.002 & $* *$ \\
\hline Newar & 0.619 & 0.210 & & 0.635 & 0.234 & \\
\hline Terai Tibeto-Burmese & 0.958 & 0.816 & & 0.956 & 0.806 & \\
\hline \multicolumn{7}{|l|}{ Respondent's marital experiences } \\
\hline Age at first marriage & 0.968 & 0.201 & & 0.968 & 0.201 & \\
\hline \multicolumn{7}{|l|}{ Marriage duration } \\
\hline Marriage duration before 1997 & 0.994 & 0.452 & & 0.995 & 0.484 & \\
\hline \multicolumn{7}{|l|}{ Marriage duration during obs. period } \\
\hline Married for $1-6$ months & 11.300 & $<0.001$ & $* * *$ & 11.311 & $<0.001$ & $* * *$ \\
\hline Married for $7-12$ months & 7.118 & $<0.001$ & $* * *$ & 7.141 & $<0.001$ & $* * *$ \\
\hline Married for $13-18$ months & 5.386 & $<0.001$ & $* * *$ & 5.387 & $<0.001$ & $* * *$ \\
\hline Married for $19-24$ months & 3.156 & $<0.001$ & $* * *$ & 3.175 & $<0.001$ & $* * *$ \\
\hline Married for $25-30$ months & 1.523 & 0.236 & & 1.540 & 0.224 & \\
\hline Married for $31-36$ months & 2.278 & 0.010 & $*$ & 2.295 & 0.010 & $* *$ \\
\hline Married for $37-42$ months & 1.300 & 0.476 & & 1.310 & 0.463 & \\
\hline \multicolumn{7}{|l|}{ Educational attainment } \\
\hline $4-7$ years of schooling & 1.621 & 0.043 & $*$ & 1.617 & 0.044 & $*$ \\
\hline $8-11$ years of schooling & 2.345 & 0.063 & . & 2.338 & 0.064 & . \\
\hline 12 or more years of schooling & 3.688 & 0.019 & $*$ & 3.669 & 0.020 & $*$ \\
\hline Intercept & 0.028 & $<0.001$ & $* * *$ & 0.022 & $<0.001$ & $* * *$ \\
\hline Degrees of freedom & & 4679 & & & 4680 & \\
\hline Residual deviance & & 1969.7 & & & 1970.2 & \\
\hline $\mathrm{AIC}$ & & 2025.7 & & & 2024.2 & \\
\hline
\end{tabular}

Two sided $\mathrm{P}$-values. Significance is coded as: $\cdot$ for $\mathrm{P}<0.1, *$ for $\mathrm{P}<0.05, * *$ for $\mathrm{P}<0.01, * * *$ for $\mathrm{P}<0.001$.

${ }^{\dagger}$ The odds-ratios for ethnicity are relative to Upper-caste Hindus.

First birth timing was modeled in a similar manner to marriage timing, by using the results of a regression model to predict the monthly probability of birth for each eligible woman for each time step. Following the results of Ghimire and Hoelter (2007) and Ghimire and Axinn (2010), we used discrete-time event history analysis to develop a regression model relating a series of covariates, including agricultural land use at the neighborhood level, to the monthly odds of a newly married woman having her first birth (Table 4). See Ghimire and Hoelter (2007) and Ghimire and Axinn (2010), for more detailed discussion of this regression model.

The regression model used in the Chitwan ABM was rerun for this paper based on the modeling strategy and controls used in panel A, model 3 in Table 2 in Ghimire and Hoelter (2007:309), to obtain the intercept for the regression equation (which was not published in Ghimire and Hoelter 2007). Because different 
Table 5. Parameter values for the three sets of scenarios. For columns 3 and 4, the first number listed in each cell is an odds ratio, and the number in parentheses is the equivalent coefficient value. The scenario set letters (A-C) are referred to in text and in later figures.

\begin{tabular}{|c|c|c|c|}
\hline Scenario set & Scenario Type & $\begin{array}{c}\text { First birth model agricultural vegetation } \\
\text { coefficient }\end{array}$ & $\begin{array}{c}\text { Marriage model agricultural vegetation } \\
\text { coefficient }\end{array}$ \\
\hline \multirow{4}{*}{$\begin{array}{c}\text { Baseline } \\
\text { A } \\
\text { (first birth timing) }\end{array}$} & Baseline & (reduced model) & (reduced model) \\
\hline & Calculated effect & $1.0057(0.0057)$ & \\
\hline & Half effect & $1.0028(0.0028)$ & (reduced model) \\
\hline & Double effect & $1.0113(0.0113)$ & \\
\hline \multirow{3}{*}{$\begin{array}{c}\mathrm{B} \\
\text { (marriage timing) }\end{array}$} & Calculated effect & & $1.1381(0.1294)$ \\
\hline & Half effect & (reduced model) & $1.0690(0.0667)$ \\
\hline & Double effect & & $1.2761(0.2438)$ \\
\hline \multirow{3}{*}{$\begin{array}{c}\mathrm{C} \\
\text { (combined) }\end{array}$} & Calculated effect & $1.0057(0.0057)$ & $1.1381(0.1294)$ \\
\hline & Half effect & $1.0028(0.0028)$ & $1.0690(0.0667)$ \\
\hline & Double effect & $1.0113(0.0113)$ & $1.2761(0.2438)$ \\
\hline
\end{tabular}

statistical software was used, the regression coefficients used here vary slightly from those in the original paper, though the significance and effect sizes for the coefficients generally agree.

An odds ratio greater than one on a covariate means that an increase in the covariate will lead to a decrease in first birth timing (by increasing the monthly probability of a first birth). We also estimate a reduced model not including the agricultural land use term (eliminating the land use - first birth timing feedback). Depending on the ABM scenario, the full or reduced model is chosen to allow or disallow a connection between agricultural land-use change and first birth timing.

At the beginning of each time step, a list was constructed of all married women who had not yet had their first birth, and who had a desired family size greater than zero. For each woman, a probability of first birth in that month was then calculated based on the values of the model covariates in that month. A random number was drawn, and if it was less than the woman's probability of first birth, she would have had a first birth in that month.

Following the first birth, additional births occurred randomly distributed on the interval of 9-48 months following the previous birth. The interval was chosen from the empirical histogram of birth intervals (see Appendix 1). The maximum total number of births per woman is limited by the woman's desired family size. Once a woman is beyond the maximum possible age to give birth (defined as age 45) or has reached her desired number of children, she is excluded from the fertility submodel.

When a new household is constructed in Chitwan, the land area it occupies is determined from a probability distribution of household land areas taken from empirical mapping data from the CVFS. To simulate land use conversion, an amount of land equal in area to the area of the new household was deducted from either the agricultural land-use category (preferentially) or the nonagricultural vegetation land use category (if insufficient agricultural land existed) and was added to the private buildings category of the appropriate neighborhood. The household was preferentially built in the husband's parent's neighborhood. If there was not enough land available in that neighborhood for this to happen, the household was located in the closest neighborhood to the household of the husband's parents that did have available land.

\section{Scenario modeling approach}

To isolate the spatial and temporal effects of feedbacks between human decision making and land use, we present three sets of scenarios in which we vary two key model parameters in a systematic manner (as seen in Table 5). In the first set of scenarios, we vary the effect size of the connection between agricultural land use and first-birth timing (scenario set "A"). Second, we vary the effect size of the connection between agricultural land use and marriage timing (scenario set "B"). Third, we vary all three of these parameters together (scenario set " $C$ "). To give an idea of the sensitivity of the model to changes in these parameters, we vary each parameter over a range around the empirically calculated value: half the calculated value, the calculated value, and double the calculated value.

For comparison with these three sets of scenarios, we ran a baseline scenario with the reduced models of marriage timing (Table 3) and first birth timing (Table 4). In the baseline scenario, agricultural land-use change by definition has no effect on first birth timing or on marriage timing, so no feedback loop exists. We eliminated the feedback loop in the baseline scenario in using the reduced models of first birth timing and marriage timing, which do not include the agricultural vegetation coefficients. Note that we did not simply set the coefficients on the agricultural vegetation covariate to zero because this would lead to an underestimation of marriage and first birth timing rates, because of the dependence of the other regression coefficients in the model on the estimated value of the agricultural vegetation coefficient. Instead we re-estimated the regression models without including the agricultural vegetation covariate.

In scenario sets A-C (Table 5) we varied the coefficients on agricultural land use in the first birth timing and marriage timing models to see if these parameter changes led to any significant differences in model outcomes when they were compared to those from the baseline. This approach tests the question of whether feedbacks between agricultural vegetation, first birth, and marriage timing affect the outcomes we observed in the model. We ran the model 40 times for each of the 10 scenarios. We present 
Table 6. Final values of women's mean first birth time, marriage age, and mean neighborhood percent agricultural vegetation for the year 2020 and the year 2050 for each of the 10 scenarios outlined in Table 5. Values are the mean values from 40 model runs of each scenario, $\pm 1.96 *$ the standard error of the mean. Values in bold vary significantly from the baseline scenario.

\begin{tabular}{|c|c|c|c|c|c|c|c|}
\hline \multirow[t]{2}{*}{ Scenario set } & \multirow[t]{2}{*}{ Scenario Type } & \multicolumn{2}{|c|}{$\begin{array}{l}\text { First birth time } \\
\text { (months) }\end{array}$} & \multicolumn{2}{|c|}{$\begin{array}{c}\text { Marriage age } \\
\text { (women only, years) }\end{array}$} & \multicolumn{2}{|c|}{$\begin{array}{l}\text { Agricultural land use } \\
\text { (percentage) }\end{array}$} \\
\hline & & 2020 & 2050 & 2020 & 2050 & 2020 & 2050 \\
\hline \multirow[t]{2}{*}{ Baseline } & No effects & 17.29 & 18.87 & 20.20 & 20.29 & 48.86 & 26.89 \\
\hline & & \pm 0.70 & \pm 0.75 & \pm 0.24 & \pm 0.20 & \pm 0.14 & \pm 0.20 \\
\hline \multirow{6}{*}{$\begin{array}{c}\text { A } \\
\text { (first birth timing) }\end{array}$} & Calculated effect & 14.65 & 16.64 & 19.95 & 20.23 & 48.62 & 26.20 \\
\hline & & \pm 0.52 & \pm 0.61 & \pm 0.20 & \pm 0.26 & \pm 0.15 & \pm 0.20 \\
\hline & Half effect & 15.12 & 17.42 & 20.08 & 20.26 & 48.62 & 26.28 \\
\hline & & \pm 0.55 & \pm 0.46 & \pm 0.25 & \pm 0.18 & \pm 0.15 & \pm 0.19 \\
\hline & Double effect & 13.23 & 17.22 & 19.93 & 20.36 & 48.61 & 25.93 \\
\hline & & \pm 0.36 & \pm 0.59 & \pm 0.17 & \pm 0.23 & \pm 0.15 & \pm 0.18 \\
\hline \multirow{6}{*}{$\frac{\mathrm{B}}{\text { (marriage timing) }}$} & Calculated effect & 17.37 & 18.37 & 20.44 & 21.00 & 48.74 & 27.03 \\
\hline & & \pm 0.56 & \pm 0.63 & \pm 0.23 & \pm 0.29 & \pm 0.15 & \pm 0.22 \\
\hline & Half effect & 17.32 & 19.19 & 20.92 & 21.25 & 49.41 & 28.53 \\
\hline & & \pm 0.82 & \pm 0.79 & \pm 0.26 & $\mathbf{\pm 0 . 1 7}$ & \pm 0.16 & \pm 0.20 \\
\hline & Double effect & 17.16 & 18.87 & 19.24 & 20.25 & 48.12 & 25.17 \\
\hline & & \pm 0.51 & \pm 0.75 & \pm 0.18 & \pm 0.22 & \pm 0.16 & \pm 0.19 \\
\hline \multirow{6}{*}{$\begin{array}{c}\mathrm{C} \\
\text { (combined) }\end{array}$} & Calculated effect & 14.36 & 16.69 & 20.26 & 21.01 & 48.82 & 26.66 \\
\hline & & \pm 0.39 & \pm 0.59 & \pm 0.20 & \pm 0.25 & \pm 0.12 & \pm 0.18 \\
\hline & Half effect & 15.57 & 17.17 & 20.74 & 21.42 & 49.44 & 28.39 \\
\hline & & \pm 0.6 & \pm 0.57 & \pm 0.21 & \pm 0.29 & \pm 0.12 & \pm 0.19 \\
\hline & Double effect & 13.64 & 16.82 & 19.08 & 20.18 & 48.08 & 24.36 \\
\hline & & \pm 0.42 & \pm 0.54 & \pm 0.19 & \pm 0.21 & \pm 0.14 & \pm 0.16 \\
\hline
\end{tabular}

the mean values from these runs of three outcome variables from the model: first birth timing, mean marriage age (women only), and mean percentage of neighborhood agricultural land use for 2020 and 2050 (Table 6). For the first birth timing and mean marriage age outcomes, we focused on women in neighborhoods that were predominantly agricultural (those in the fourth quartile of neighborhoods based on percentage agricultural cover in 1996), because these women were most likely to be influenced by any feedbacks of agricultural land-use change. All results stated to be "statistically significant" are significant at $\mathrm{P} \leq 0.05$ based on a two-tailed t-test.

\section{RESULTS}

In scenario set A (first birth timing), we examined three different scenarios including a link between agricultural land use and first birth timing. The outcome, mean percentage of neighborhood agricultural land use, was calculated by summing the fraction of land devoted to agriculture (as a percentage) across all neighborhoods, and dividing by the total number of neighborhoods (to get the mean). We used this outcome rather than change in total land area because it is a better indicator of changing community context. In all three scenarios, the percentage of agricultural land remaining in 2050 was significantly lower than in the baseline scenario, in which no link exists between agricultural land use and first birth timing. Agricultural land use declined to $26.20 \% \pm 0.20 \%$ in the calculated effect scenario, to $26.28 \% \pm 0.19 \%$ in the half effect scenario, and to $25.93 \% \pm 0.18 \%$ in the double effect scenario.

In set B (marriage timing), we varied the size of the coefficient linking marriage timing and agricultural land use. Again 2050 land use differed significantly from the baseline under all three scenarios, but in this case the percentage of remaining agricultural land was higher than the baseline in the calculated effect $(27.03 \%$ $\pm 0.22 \%)$ and half effect $(28.53 \% \pm 0.20 \%)$ scenarios, and lower than the baseline in the double effect scenario $(25.17 \% \pm 0.19 \%)$.

In set $\mathrm{C}$ (combined), we varied both parameters together. When the calculated effect sizes were used in the marriage timing and first birth timing models, agricultural land use in $2050(26.66 \%$ $\pm 0.18 \%$ ) did not vary significantly from the baseline. Agricultural land use in 2050 in set $\mathrm{C}$ differed significantly from the baseline only under the half effect $(28.39 \% \pm 0.19 \%$, higher than the baseline) and double effect $(24.36 \% \pm 0.16 \%$, lower than the baseline) scenarios.

In Figure 3, we plot the total population (left side of Fig. 3) and the mean percentage neighborhood agricultural land use (right side of Fig. 3). These figures give a qualitative view of the dynamics of land-use change over the 53-year model run (see above for a discussion of the statistical significance of 2020 and 2050 outcomes). Each line of Figure 3 represents the mean value from 40 model runs. The shaded error bars represent $\pm 1.96 *$ the standard error of the mean of the 40 model runs.

First, we considered the population outcomes from the three set of scenarios (left side of Fig. 3). Including the positive effect of agricultural vegetation (Scenario set A) on first birth timing led to a significantly higher 2050 population $(24,592$ in the calculated effect scenario) compared to the baseline $(23,609)$. Including the positive effect of agricultural vegetation on marriage timing (Scenario set B) led to a reduction in population (22,787 in 2050) compared to the baseline. In the combined scenario (Scenario set C), we saw a small, but statistically significant, decrease in population from the baseline $(23,461$ in 2050$)$.

Next, we considered the land-use outcomes from the three set of scenarios (right side of Fig. 3). When we included the positive effect of agricultural vegetation on first birth timing, we saw little 
Fig. 3. Population (left) and agricultural vegetation (right) plotted for the three sets of scenarios over a 53-year model run (1997-2050).
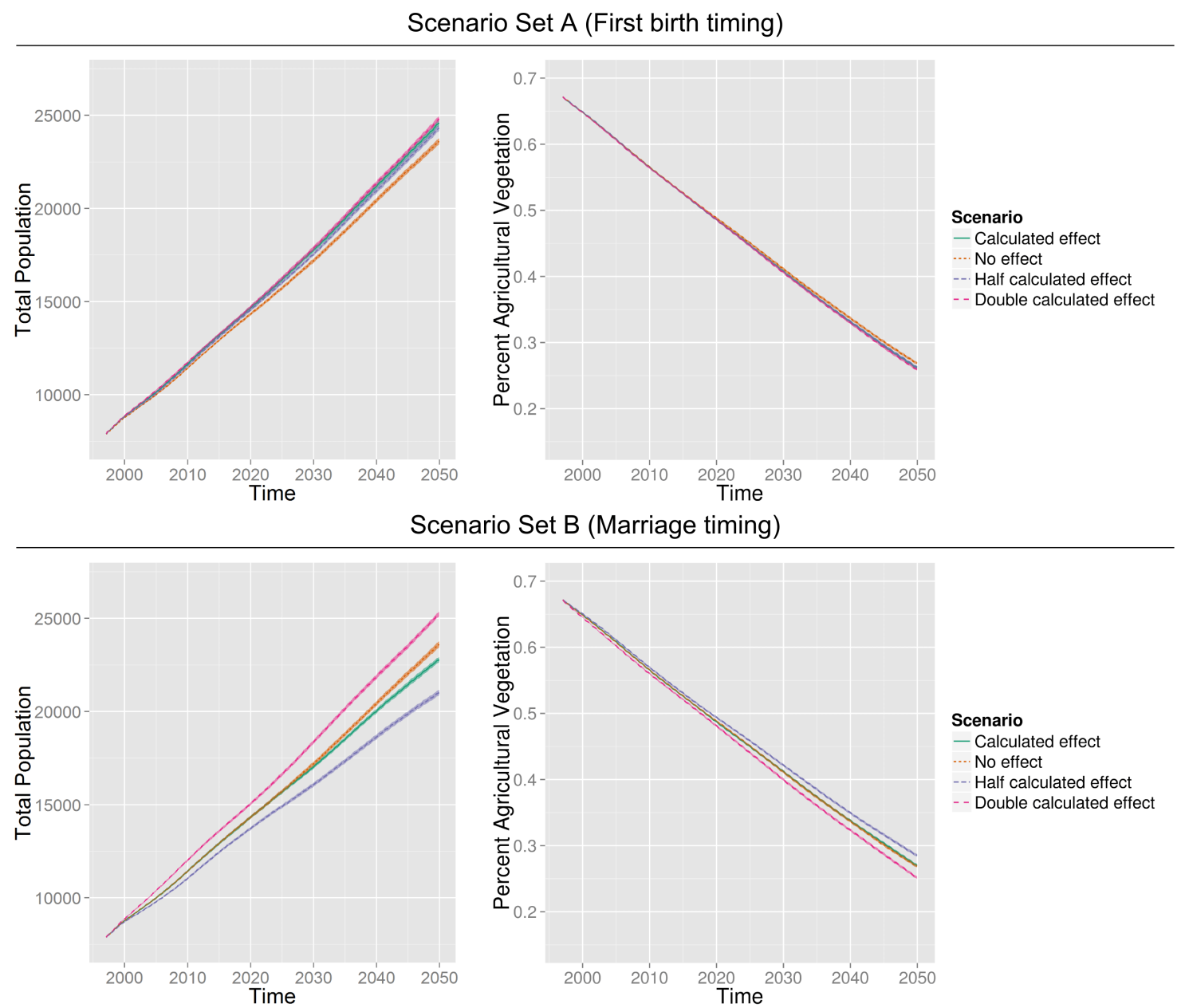

\section{Scenario}

- Calculated effect

No effect

- Half calculated effect

- Double calculated effect

Scenario Set C (Combined scenarios)
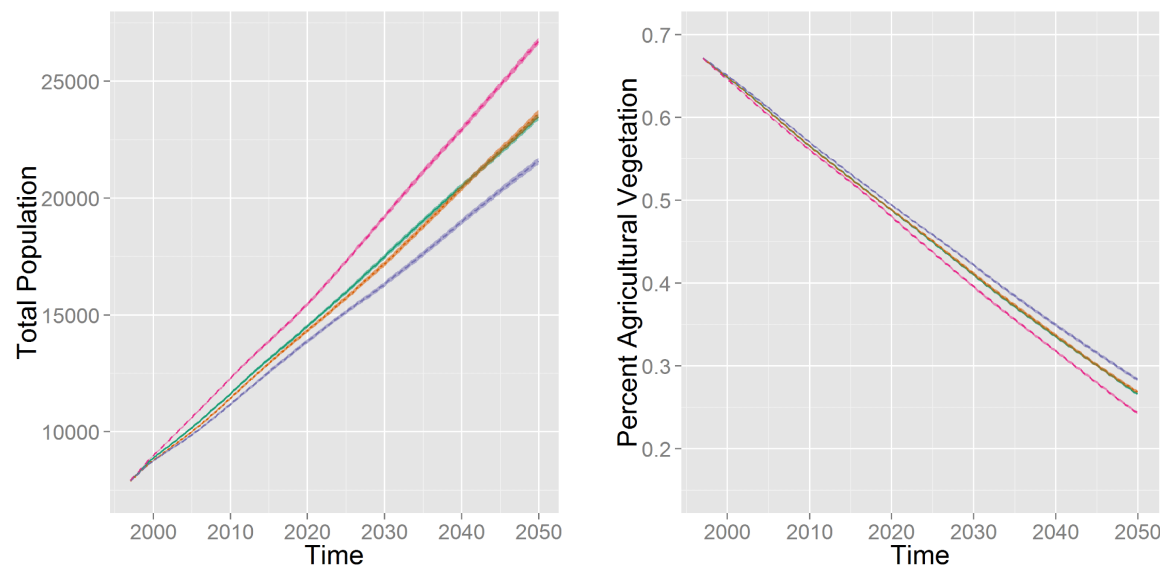

\section{Scenario}

- Calculated effects

No effects

Half calculated effects

- - Double calculated effects

difference in agricultural land-use change between the baseline, calculated, half, and double effect scenarios. When we included the positive effect of agricultural vegetation on marriage timing, the calculated effect scenario did not vary significantly from the baseline; however, the half effect scenario showed a slight decrease in conversion of agricultural land, while the double effect scenario 
showed a slight increase. In the combined scenarios, we saw large differences between the double effect and half effect scenarios, but little difference between the calculated effect scenario and the baseline.

To look in detail at feedbacks between first birth timing and land use, we plotted the mean number of months from marriage to first birth for women in predominantly agricultural neighborhoods, for women from scenario set A (Fig. 4). As accurate marriage dates were not known for women prior to the beginning of the model, we focused on women married on or after the first time step of the model; for this reason the mean first birth time appeared to rise until about 2001. This is because it takes a number of time steps for women married on or after the first time step (February 1997) to begin to experience their first births after marrying. We see in Figure 4 the effect of including the link between first birth timing and land use: at the beginning of the no effect scenario model run, women have their first birth, on average, 18 months after marriage. Using the calculated effect size for the first birth timing-land use coefficient leads to a first birth timing of 15 months. The calculated effect, half effect, and double effect scenarios all show steady increases in mean first birth times throughout the duration of the model run; this is in response to the effect of agricultural land-use change on first birth timing. As agricultural land decreases, women begin to delay births.

Fig. 4. First birth timing for women in agricultural neighborhoods, plotted for the four scenarios in scenario set 'A.

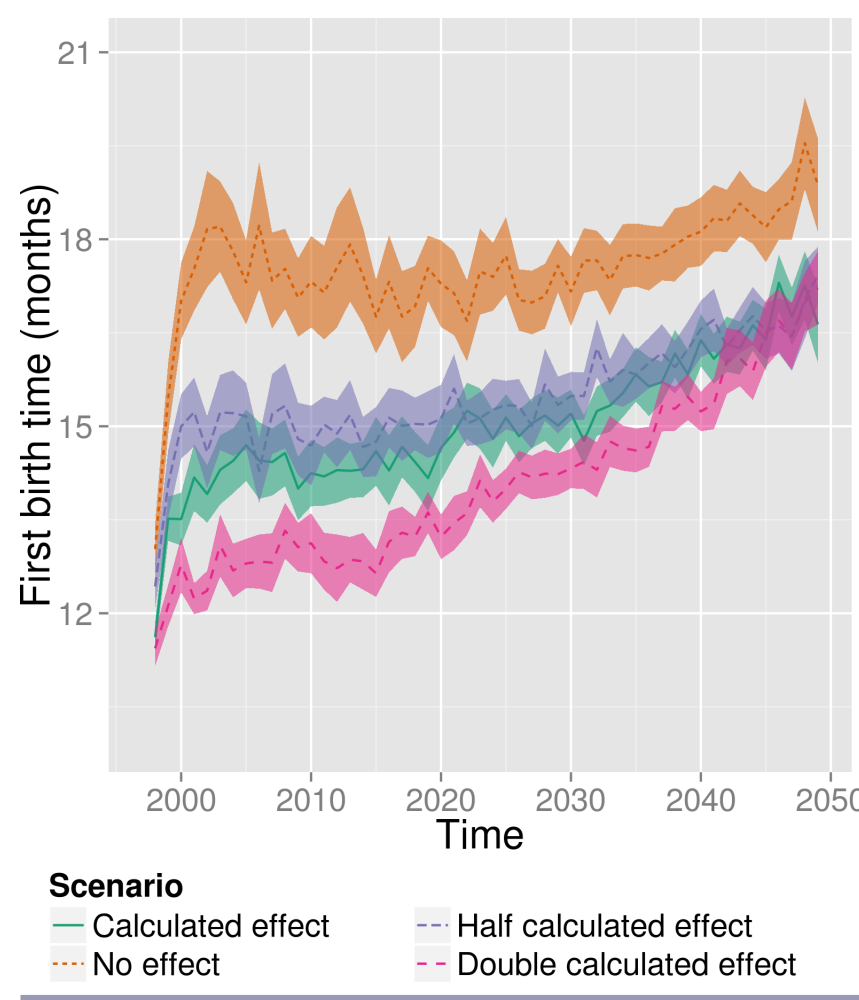

We saw the effect of including the connection between agricultural land-use change and first birth timing quite clearly; when the connection is included, land-use change over the course of the model leads to an increase in first birth times of four months over the duration of the model run (Fig. 4). Any delay in first births after marriage decreases the total time a woman is subject to the fertility model. Therefore this increase in first birth time should act as a negative feedback on transition of land out of agriculture by slowing population increase, and therefore slowing new household formation. However, instead we saw a slight increase in 2050 population compared to the baseline when the effect was included, and a resultant very slight increase in conversion of land out of agriculture.

Last, we considered the difference in marriage age between the scenarios in set $\mathrm{B}$, where the effect of agricultural land use on marriage timing is varied. In Figure 5 we plot the mean marriage age for women in predominantly agricultural neighborhoods from scenario set B, for women who reached the earliest possible marriage age (defined in the model as 15) on or after the first time step of the model. This ensures that the sample of women shown in Figure 5 was exposed to the Chitwan ABM marriage model for the entire time they were eligible for marriage. The rapid rise in mean marriage age that appeared to occur until 2010 was a byproduct of this restriction, not a real phenomenon in the model. As expected, under the no effect scenario marriage ages did not vary over time, and were significantly lower in 2050 than under the calculated effect scenario. The double calculated effect scenario showed the lowest initial marriage age, but most rapid rise over time because of the effect of agricultural land-use change on marriage timing.

Fig. 5. Mean marriage age for women in predominantly agricultural neighborhoods, plotted for the four scenarios in scenario set 'B.'

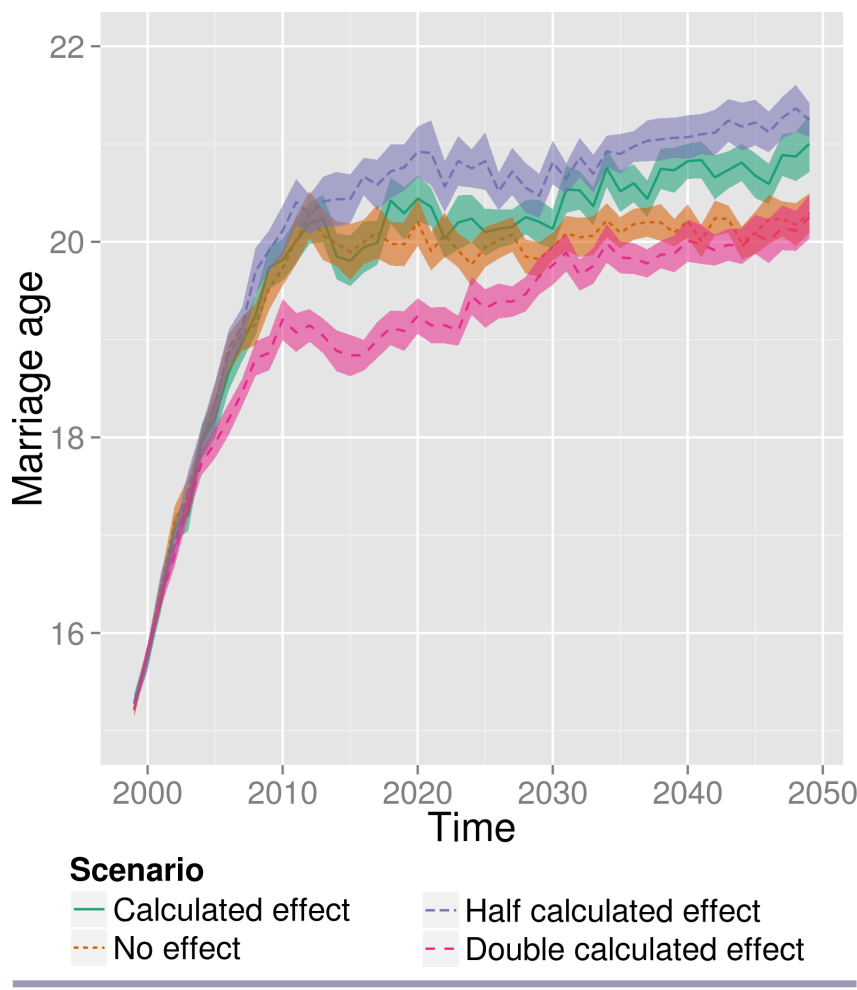


In set $\mathrm{B}$, we saw the effect of including the connection between agricultural land use and marriage age (Fig. 5). When the calculated effect size was used, marriage age increased by approximately a year over the duration of the model run. This increase should have acted as a negative feedback on agricultural land transition by directly slowing new household formation, and indirectly by slowing population increase. As expected, we saw a slight decline in 2050 population when the effect was included, and a slight, though not statistically significant, increase in 2050 agricultural land (Fig. 3).

\section{DISCUSSION}

The Chitwan ABM integrates social and environmental data to consider the role of feedbacks between population and environment in land change. The unusual level of detail in the demographic components of the model allows us to test the role of very specific microscale connections (first-birth timing agricultural land use and marriage-timing - agricultural land use) in affecting broader scale land cover change while controlling for individual, household, and neighborhood level factors that also influence human decision making. Our results indicate that feedbacks between agricultural land use and marriage timing and between agricultural land use and first birth timing lead to statistically significant differences in population and in land use. This result confirms that changing microlevel demographic processes can be significantly linked with broader scale LULC change (Carr 2004).

Although the effects of land-use change are clearly present in the model outcomes they directly affect (first birth timing and marriage timing) the effects of the hypothesized negative feedbacks loops between population change and land use is less clear. Though statistically significant differences exist in model outcomes between the baseline scenarios not including the feedback loops and the scenarios including the feedback loops, the differences are relatively small (differences in observed land use relative to the baseline ranging from $-5.25 \%$ to $7.36 \%$ over 53 years). This could be due to the outcomes chosen here; for this paper first birth timing and marriage timing were chosen for the express purpose of investigating indirect linkages between decisions and land use. New household formation after marriage (household fission), as the primary direct determinant of landuse change in the Chitwan ABM, has a large effect on land use because of its direct connection to land clearing for new households. Were potential feedbacks between environmental change and household fission included in the model, the effect of the feedbacks would likely be more pronounced. Future work with the Chitwan ABM could include a direct representation of fuelwood and fodder collection processes in the Chitwan Valley, allowing a more direct link between changing demographics, resource collection practices, and environmental change.

However, understanding weak feedbacks resulting from indirect couplings is a continuing challenge in CHANS research (Chin et al. 2014). The results of this paper suggest that indirect couplings can result in statistically significant differences in the observed states of CHANS over sufficiently long (decadal in this case) time scales. The time lag before differences in land use were observed between the baseline and feedback scenarios in this analysis is similar to the findings of Le et al. (2012), who used an ABM to consider the effects of two different types of adaptation processes (one reactive, the other a learning process), finding that each process lead to alternative pathways of land-use change over a decadal time scale.

The small size of the difference between the land-use outcomes in the range of scenarios examined here is perhaps unsurprising given the small per unit size of the effects of land use change on marriage and first birth timing in the regression models presented earlier. In the first birth model, for example, a $1 \%$ increase in agriculture leads to an increase of only $0.6 \%$ in the hazard of a first birth in a given month (Table 4). There are numerous factors that affect an individual's decision to have a child, many of which are represented in the regression model used to parameterize the ABM presented here. Several of these factors have much larger effects on marriage or birth timing than does changing agricultural land use, e.g., marriage duration and education.

Though the potential exists for weak feedbacks to lead to significant changes in observed land use outcomes over a significantly long time scale, when considering regression and ABM results with the goal of informing policy it is important not to lose sight of the larger picture. Though we may find noteworthy couplings within systems, such as the two feedbacks examined here, if these feedbacks are weak, their effect on system dynamics may be dwarfed over long time scales by other feedback processes and other changes in factors more directly connected to human and landscape change. In the case of the Chitwan Valley, increasing access to education and off-farm employment, for example, could be expected to have larger long time scale effects on land-use change than the feedbacks we describe here.

This result should not be taken to mean that weak feedbacks in general are not important. However, it is a reminder that we must carefully consider the results of statistical models, including both effect size and significance, particularly when making policy recommendations regarding the long time scale dynamics of population and environment change. Although a regression model, for example, may reveal a covariate to be a statistically significant predictor of a given outcome, we must take a holistic view of the system to evaluate the importance of the covariate in terms of its effects on the long-term evolution of a system.

One limitation of this study that must be kept in mind is the assumption we make that relationships are constant over the 53year time span of the model. Changes in local livelihoods due to increased market access, and the effects of increasing international migration on the local economy are just two areas that deserve additional attention. Further studies to allow demographic processes, such as migration, and livelihood strategies to vary in response to socioeconomic change are ongoing. It is also possible that feedbacks could exist between environmental change and the structure of decision models; as an area urbanizes, for example, we might expect the effect of land cover change on fertility decisions to vary in time. Further study of the effect of allowing variation in the structure of decision models over time would be a fruitful area for additional research.

Finally, when interpreting ABM model results the structure of the ABM and the approach used to parameterize the model must be taken into account. A particular concern in modeling CHANS is how to represent human decision-making models (An and López-Carr 2012). One approach for model parameterization is 
to build a rule-based model, in which, for example, heuristic rules or preference-based decision models might be used to model agent behaviors (An 2012). Given our interest in building an empirically grounded ABM with which to test the effects of empirically observed relationships, such as the first-birth timing and marriage-timing feedbacks we explore here, we use a different approach. In the Chitwan ABM, stochastic process models are used to model events, with probabilities of event occurrences determined from statistical analyses of empirical data. We include in the statistical models covariates selected based on current theoretical understanding of the processes we model. This approach allows us to control in each decision model for a range of covariates that might influence human decisions, allowing us to isolate and examine particular relationships in the model.

\section{CONCLUSION}

To investigate the role of feedbacks between land use and microscale decision making (marriage timing) on the emergent dynamics of land use and population, we constructed an ABM of a CHANS in the Chitwan Valley, Nepal. Prior work has suggested that land conversion out of agriculture in Chitwan might act as a negative feedback on future land-use change, by increasing the time from marriage until the first birth (Ghimire and Axinn 2010), and by increasing the age of marriage (Yabiku 2006a). Population and land-use outcomes were compared from a set of 53-year model runs from models run both with and without inclusion of an effect of land-use change on fertility and marriage timing. Population and environment researchers have recognized that connections in CHANS "are not unidirectional but reciprocal" (de Sherbinin et al. 2007:363). The framework adopted here enables a direct look at the impact of feedbacks on decadal scale dynamics of a CHANS.

Our work concluded that feedbacks between land-use change and individual-level marriage and fertility decision-making can lead to significant, though small, differences in model outcomes, with the mean percent of neighborhood land devoted to agriculture varying significantly $(\mathrm{p}<0.001)$ from the baseline when feedbacks are included, from $-5.25 \%$ lower to $7.36 \%$ higher than baseline, with the size of the difference depending on the calculated effect size. The small size of these differences should not be taken to mean that feedbacks in general are not important. However, it is a reminder that analysts and policy makers must carefully consider the results of statistical models and ABMs, including both effect size and significance, particularly when making policy recommendations regarding the long time scale dynamics of CHANS

The research here focused on two specific couplings: further work is needed on the dynamic effects of other couplings that have already been uncovered in the population and environment literature, such as links between migration and land use and cover change. Additional consideration is also needed on the effects of spatially varying relationships in CHANS and on the effects of alternative decision models that might exist in different groups of agents, such as in groups defined by ethnicity or educational background. López-Carr et al. (2012) showed using multilevel modeling and geographically weighted regression (GWR) that the direction of relationships between socioeconomic indicators and land-use change can vary spatially. Similarly, we might expect the determinants of marriage timing and fertility preferences to vary depending on household-level livelihood strategies. The mixed regression models used to parameterize the Chitwan ABM capture linear relationships between the predictors in the model and observed marriage timing and fertility decisions; future work to allow decision models to vary between groups might reveal further dynamic complexity.

Responses to this article can be read online at: http://www.ecologyandsociety.org/issues/responses. $\mathrm{php} / 6243$

\section{Acknowledgments:}

We thank the National Science Foundation for support under the Partnerships for International Research and Education (PIRE) program (OISE 0729709). We also thank the Inamori Foundation, San Diego State University Graduate Student Travel Fund, and University of California, Santa Barbara Graduate Council for additional support of Alex Zvoleff's field research in Nepal. The PIRE project team, including William Axinn, Jianguo Liu, Lisa Pearce, Scott Yabiku, and Dirgha Ghimire provided essential input during the development of the Chitwan ABM model, and aided in evaluating the model results. We thank Kathleen Farley and David López-Carr for their input on the draft manuscript, as well as the editor and four anonymous reviewers for their comments and suggestions. We thank the staff at the Institute for Social and Environmental Research-Nepal for their support of data collection in Nepal, and the researchers at the Nepal Department of National Parks and Wildlife Conservation for their ongoing support of our work.

\section{LITERATURE CITED}

Acevedo, M. F., J. B. Callicott, M. Monticino, D. Lyons, J. Palomino, J. Rosales, L. Delgado, M. Ablan, J. Davila, G. Tonella, H. Ramírez, and E. Vilanova. 2008. Models of natural and human dynamics in forest landscapes: cross-site and cross-cultural synthesis. Geoforum 39:846-866.

Aide, T. M., and H. R. Grau. 2004. Globalization, migration, and Latin American ecosystems. Science 305:1915-1916. http://dx. doi.org/10.1126/science.1103179

Alberti, M., H. Asbjornsen, L. A. Baker, N. Brozovic, L. E. Drinkwater, S. A. Drzyzga, C. A. Jantz, J. Fragoso, D. S. Holland, T. A. Kohler, J. Liu, W. J. McConnell, H. D. G. Maschner, J. D. A. Millington, M. Monticino, G. Podestá, R. G. Pontius, Jr., C. L. Redman, N. J. Reo, D. Sailor, and G. Urquhart. 2011. Research on coupled human and natural systems (CHANS): approach, challenges, and strategies. Bulletin of the Ecological Society of America 92:218-228. http://dx.doi.org/10.1890/0012-9623-92.2.218

An, L. 2012. Modeling human decisions in coupled human and natural systems: review of agent-based models. Ecological Modelling 229:25-36. http://dx.doi.org/10.1016/j.ecolmodel.2011.07.010

An, L., M. A. Linderman, J. Qi, A. Shortridge, and J. Liu. 2005. Exploring complexity in a human environment system: an agentbased spatial model for multidisciplinary and multiscale integration. Annals of the Association of American Geographers 95:54-79. http://dx.doi.org/10.1111/j.1467-8306.2005.00450.x 
An, L., and J. Liu. 2010. Long-term effects of family planning and other determinants of fertility on population and environment: agent-based modeling evidence from Wolong Nature Reserve, China. Population and Environment 31:427-459. http://dx.doi.org/10.1007/s11111-010-0111-3

An, L., and D. López-Carr. 2012. Understanding human decisions in coupled natural and human systems. Ecological Modelling 229:1-4. http://dx.doi.org/10.1016/j.ecolmodel.2011.10.023

An, L., A. Zvoleff, J. Liu, and W. G. Axinn. In press. Agent based modeling in coupled human and natural systems (CHANS): lessons from a comparative analysis. Annals of the Association of American Geographers.

Axinn, W. G., and D. J. Ghimire. 2007. Social organization, population, and land use. Population Studies Center, University of Michigan, Ann Arbor, Michigan, USA.

Axinn, W. G., A. Thornton, J. S. Barber, S. A. Murphy, D. J. Ghimire, T. Fricke, S. Matthews, D. R. Dangol, L. D. Pearce, A. Biddlecom, S. Shrehtha, and D. Massey. 2011. Chitwan Valley family study. Population Studies Center and Survey Research Center, University of Michigan, Ann Arbor, Michigan, USA.

Axtell, R. L., J. M. Epstein, J. S. Dean, G. J. Gumerman, A. C. Swedlund, J. Harburger, S. Chakravarty, R. Hammond, J. Parker, and M. Parker. 2002. Population growth and collapse in a multiagent model of the Kayenta Anasazi in Long House Valley. Proceedings of the National Academy of Sciences 99:7275-7279.

Barber, J. S., G. P. Shivakoti, W. G. Axinn, and K. Gajurel. 1997. Sampling strategies for rural settings: a detailed example from Chitwan Valley Family Study, Nepal. Nepal Population Journal 6:193-203.

Barbieri, A. F., R. E. Bilsborrow, and W. K. Pan. 2005. Farm household lifecycles and land use in the Ecuadorian Amazon. Population and Environment 27:1-27. http://dx.doi.org/10.1007/ $\underline{\mathrm{s} 11111-005-0013-\mathrm{y}}$

Barbieri, A. F., D. L. Carr, and R. E. Bilsborrow. 2009. Migration within the frontier: the second generation colonization in the Ecuadorian Amazon. Population Research and Policy Review 28:291-320. http://dx.doi.org/10.1007/s11113-008-9100-y

Bearer, S., M. Linderman, J. Huang, L. An, G. He, and J. Liu. 2008. Effects of fuelwood collection and timber harvesting on giant panda habitat use. Biological Conservation 141:385-393. http://dx.doi.org/10.1016/j.biocon.2007.10.009

Brown, D. G., and D. T. Robinson. 2006. Effects of heterogeneity in residential preferences on an agent-based model of urban sprawl. Ecology and society 11(1): 46. [online] URL: http://www. ecologyandsociety.org/vol11/iss1/art46/

Caldas, M., R. Walker, E. Arima, S. Perz, S. Aldrich, and C. Simmons. 2007. Theorizing land cover and land use change: the peasant economy of Amazonian deforestation. Annals of the Association of American Geographers 97:86-110. http://dx.doi. org/10.1111/j.1467-8306.2007.00525.x

Carr, D. 2009. Population and deforestation: why rural migration matters. Progress in Human Geography 33:355-378. http://dx.doi. org/10.1177/0309132508096031
Carr, D. L. 2004. Proximate population factors and deforestation in tropical agricultural frontiers. Population and Environment 25:585-612. http://dx.doi.org/10.1023/B:POEN.0000039066.05666.8d

Carter, N. H., B. K. Shrestha, J. B. Karki, N. M. B. Pradhan, and J. Liu. 2012. Coexistence between wildlife and humans at fine spatial scales. Proceedings of the National Academy of Sciences. http://dx.doi.org/10.1073/pnas. 1210490109

Central Bureau of Statistics (CBS). 1991. Population census 1999. Nepal Central Bureau of Statistics, Government of Nepal National Planning Commission Secretariat, Thapathali, Kathmandu.

Central Bureau of Statistics (CBS). 2001. Population census 2001.

Nepal Central Bureau of Statistics, Government of Nepal National Planning Commission Secretariat, Thapathali, Kathmandu.

Central Bureau of Statistics (CBS). 2012. National population and housing census 2011. Central Bureau of Statistics. Government of Nepal, National Planning Commission Secretariat, Kathmandu, Nepal.

Chen, X., F. Lupi, L. An, R. Sheely, A. Viña, and J. Liu. 2012. Agent-based modeling of the effects of social norms on enrollment in payments for ecosystem services. Ecological Modelling 229:16-24. http://dx.doi.org/10.1016/j.ecolmodel.2011.06.007

Chin, A., J. L. Florsheim, E. Wohl, and B. D. Collins. 2014. Feedbacks in human-landscape systems. Environmental Management 53:28-14. http://dx.doi.org/10.1007/s00267-013-0031y

Deadman, P., D. Robinson, E. F. Moran, and E. Brondizio. 2004. Colonist household decisionmaking and land-use change in the Amazon Rainforest: an agent-based simulation. Environment and Planning B Planning and Design 31:693-709. http://dx.doi. org/10.1068/b3098

de Sherbinin, A., D. Carr, S. Cassels, and L. Jiang. 2007. Population and environment. Annual Review of Environment and Resources 32:345-373. http://dx.doi.org/10.1146/annurev. energy.32.041306.100243

Entwisle, B., G. P. Malanson, R. R. Rindfuss, and S. J. Walsh. 2008. An agent-based model of household dynamics and land use change. Journal of Land Use Science 3:73-93. http://dx.doi. org/10.1080/17474230802048193

Evans, T. P., and H. Kelley. 2008. Assessing the transition from deforestation to forest regrowth with an agent-based model of land cover change for south-central Indiana (USA). Conversations Across the Divide; The Time and Place for Political Ecology: The Life-Work of Piers Blaikie; Biocomplexity in Coupled Human-Natural Systems: The Study of PopulationEnvironment Interactions. Geoforum 39:819-832. http://dx.doi. org/10.1016/j.geoforum.2007.03.010

Folke, C. 2006. Resilience: the emergence of a perspective for social-ecological systems analyses. Global Environmental Change 16:253-267. http://dx.doi.org/10.1016/j.gloenvcha.2006.04.002

Ghimire, D. J., and W. G. Axinn. 2010. Community context, land use, and first birth. Rural Sociology 75:478-513. http://dx.doi. org/10.1111/j.1549-0831.2010.00019.x 
Ghimire, D. J., and L. F. Hoelter. 2007. Land use and first birth timing in an agricultural setting. Population \& Environment 28:289-320. http://dx.doi.org/10.1007/s11111-007-0056-3

Grimm, V., U. Berger, F. Bastiansen, S. Eliassen, V. Ginot, J. Giske, J. Goss-Custard, T. Grand, S. K. Heinz, G. Huse, A. Huth, J. U. Jepsen, C. Jørgensen, W. M. Mooij, B. Müller, G. Pe'er, C. Piou, S. F. Railsback, A. M. Robbins, M. M. Robbins, E. Rossmanith, N. Rüger, E. Strand, S. Souissi, R. A. Stillman, R. Vabø, U. Visser, and D. L. DeAngelis. 2006. A standard protocol for describing individual-based and agent-based models. Ecological Modelling 198:115-126. http://dx.doi.org/10.1016/i.ecolmodel.2006.04.023

Grimm, V., U. Berger, D. L. DeAngelis, J. G. Polhill, J. Giske, and S. F. Railsback. 2010. The ODD protocol: a review and first update. Ecological Modelling 221:2760-2768. http://dx.doi. org/10.1016/j.ecolmodel.2010.08.019

He, G., X. Chen, S. Bearer, M. Colunga, A. Mertig, L. An, S. Zhou, M. Linderman, Z. Ouyang, S. Gage, S. Li, and J. Liu. 2009. Spatial and temporal patterns of fuelwood collection in Wolong Nature Reserve: implications for panda conservation. Landscape and Urban Planning 92:1-9. http://dx.doi.org/10.1016/j. landurbplan.2009.01.010

Horan, R. D., E. P. Fenichel, K. L. S. Drury, and D. M. Lodge. 2011. Managing ecological thresholds in coupled environmentalhuman systems. Proceedings of the National Academy of Sciences 108:7333-7338. http://dx.doi.org/10.1073/pnas.1005431108

Jarvis, A. J., D. T. Leedal, and C. N. Hewitt. 2012. Climate-society feedbacks and the avoidance of dangerous climate change. Nature Climate Change 2:668-671.

Lambin, E. F., B. L. Turner, H. J. Geist, S. B. Agbola, A. Angelsen, J. W. Bruce, O. T. Coomes, R. Dirzo, G. Fischer, C. Folke, P. S. George, K. Homewood, J. Imbernon, R. Leemans, X. Li, E. F. Moran, M. Mortimore, P. S. Ramakrishnan, J. F. Richards, H. Skånes, W. Steffen, G. D. Stone, U. Svedin, T. A. Veldkamp, C. Vogel, and J. Xu. 2001. The causes of land-use and land-cover change: moving beyond the myths. Global Environmental Change 11:261-269. http://dx.doi.org/10.1016/S0959-3780(01)00007-3

Le, Q. B., R. Seidl, and R. W. Scholz. 2012. Feedback loops and types of adaptation in the modelling of land-use decisions in an agent-based simulation. Environmental Modelling \& Software 27-28:83-96. http://dx.doi.org/10.1016/j.envsoft.2011.09.002

Linderman, M. A., L. An, S. Bearer, G. He, Z. Ouyang, and J. Liu. 2005. Modeling the spatio-temporal dynamics and interactions of households, landscapes, and giant panda habitat. Ecological Modelling 183:47-65. http://dx.doi.org/10.1016/j. ecolmodel.2004.07.026

Liu, J., G. C. Daily, P. R. Ehrlich, and G. W. Luck. 2003. Effects of household dynamics on resource consumption and biodiversity. Nature 421:530-533. http://dx.doi.org/10.1038/ $\underline{\text { nature } 01359}$

Liu, J., T. Dietz, S. R. Carpenter, M. Alberti, C. Folke, E. F. Moran, A. N. Pell, P. Deadman, T. Kratz, J. Lubchenco, E. Ostrom, Z. Ouyang, W. Provencher, C. L. Redman, S. H. Schneider, and W. W. Taylor. 2007. Complexity of coupled human and natural systems. Science 317:1513-1516. http://dx.doi. org/10.1126/science. 1144004
Liu, J., M. Linderman, Z. Ouyang, L. An, J. Yang, and H. Zhang. 2001. Ecological degradation in protected areas: the case of Wolong Nature Reserve for giant pandas. Science 292:98-101. http://dx.doi.org/10.1126/science.1058104

Liu, J., and W. W. Taylor. 2002. Coupling landscape ecology with natural resource management: paradigm shifts and new approaches. Pages 3-20 in J. Liu and W. W. Taylor, editors. Integrating landscape ecology into natural resource management. Cambridge University Press, Cambridge, UK. http://dx.doi. org/10.1017/CBO9780511613654.003

López-Carr, D., J. Davis, M. M. Jankowska, L. Grant, A. C. López-Carr, and M. Clark. 2012. Space versus place in complex human-natural systems: spatial and multi-level models of tropical land use and cover change (LUCC) in Guatemala. Ecological Modelling 229:64-75. http://dx.doi.org/10.1016/j. ecolmodel.2011.08.020

Manson, S. M., S. Sun, and D. Bonsal. 2012. Agent-based modeling and complexity. Pages 125-139 in A. J. Heppenstall, A. T. Crooks, L. M. See, and M. Batty, editors. Agent-based models of geographical systems. Springer, Dordrecht, The Netherlands. http://dx.doi.org/10.1007/978-90-481-8927-4 7

Massey, D. S., W. G. Axinn, and D. J. Ghimire. 2010. Environmental change and out-migration: evidence from Nepal. Population and Environment 32:109-136. http://dx.doi.org/10.1007/ $\underline{\text { s11111-010-0119-8 }}$

Miller, B. W., S. C. Caplow, and P. W. Leslie. 2012. Feedbacks between conservation and social-ecological systems. Conservation Biology 26:218-227. http://dx.doi.org/10.1111/j.1523-1739.2012.01823. $\underline{\mathrm{X}}$

Parker, D. C., S. M. Manson, M. A. Janssen, M. J. Hoffmann, and P. Deadman. 2003. Multi-agent systems for the simulation of land-use and land-cover change: a review. Annals of the Association of American Geographers 93:314-337. http://dx.doi. org/10.1111/1467-8306.9302004

Rindfuss, R. R. 1991. The young adult years: diversity, structural change, and fertility. Demography 28:493-512. http://dx.doi. org/10.2307/2061419

Rindfuss, R. R., B. Entwisle, S. J. Walsh, L. An, N. Badenoch, D. G. Brown, P. Deadman, T. P. Evans, J. Fox, J. Geoghegan, M. Gutmann, M. Kelly, M. A. Linderman, J. Liu, G. P. Malanson, C. F. Mena, J. P. Messina, E. F. Moran, D. C. Parker, W. Parton, P. Prasartkul, D. T. Robinson, Y. Sawangdee, L. K. Vanwey, and P. H. Verburg. 2008. Land use change: complexity and comparisons. Journal of Land Use Science 3:1-10. http://dx.doi. org/10.1080/17474230802047955

Schmolke, A., P. Thorbek, D. L. DeAngelis, and V. Grimm. 2010. Ecological models supporting environmental decision making: a strategy for the future. Trends in Ecology \& Evolution 25:479-486. http://dx.doi.org/10.1016/j.tree.2010.05.001

VanWey, L. K. 2003. Land ownership as a determinant of temporary migration in Nang Rong, Thailand. European Journal of Population/Revue européenne de Démographie 19:121-145. http://dx.doi.org/10.1023/A:1023307100719 
Walker, R., S. Perz, M. Caldas, and L. G. T. Silva. 2002. Land use and land cover change in forest frontiers: the role of household life cycles. International Regional Science Review 25:169-199. http://dx.doi.org/10.1177/016001760202500202

Walsh, S. J., J. P. Messina, C. F. Mena, G. P. Malanson, and P. H. Page. 2008. Complexity theory, spatial simulation models, and land use dynamics in the Northern Ecuadorian Amazon. Geoforum 39:867-878. http://dx.doi.org/10.1016/j.geoforum.2007.02.011

Werner, B. T., and D. E. McNamara. 2007. Dynamics of coupled human-landscape systems. Geomorphology 91:393-407. http://dx. doi.org/10.1016/j.geomorph.2007.04.020

Yabiku, S. T. 2006a. Land use and marriage timing in Nepal. Population \& Environment 27:445-461. http://dx.doi.org/10.1007/ $\underline{\text { s11111-006-0030-5 }}$

Yabiku, S. T. 2006b. Neighbors and neighborhoods: effects on marriage timing. Population Research and Policy Review 25:305-327. http://dx.doi.org/10.1007/s11113-006-9006-5

Zvoleff, A., and L. An. 2014. Analyzing human-landscape interactions: tools that integrate. Environmental Management 53:94-111. http://dx.doi.org/10.1007/s00267-012-0009-1

Zvoleff, A., L. An, J. Stoler, and J. R. Weeks. 2013. What if neighbors' neighborhoods differ? The influence of neighborhood definition on health outcomes in Accra. Pages 125-142 in J. R. Weeks, A. G. Hill, and J. Stoler, editors. Spatial inequalities: health, poverty and place in Accra, Ghana. Springer, Dordrecht, The Netherlands. http://dx.doi.org/10.1007/978-94-007-6732-48 


\section{Appendix 1.}

Overview, Design Concepts, and Details (ODD) of the Chitwan ABM.

\section{OVERVIEW}

Following the Overview, Design concepts, and Details (ODD) model description framework (Grimm et al. 2006, 2010), this section describes the purpose, entities, state, variables, and scales, and the processes of the Chitwan ABM. The model code is available online at http://www.openabm.org/model/3640.

\section{Purpose}

The Chitwan ABM was constructed to explore the role of feedbacks between land-use and demographic change in determining decadal scale dynamics of land-use and land-cover change in the Chitwan Valley. The model is intended to be used as a laboratory for testing the relative effect of different drivers of demographic and land use and cover change, and for the exploration of alternative development scenarios.

We represent the sample of the Chitwan Valley Family Study (CVFS) using a nested hierarchical structure of individual people nested within households, nested within their broader neighborhood ( $\sim 500 \mathrm{~m}$ radius spatial scale). Consistent with this analysis and with past findings from the literature, we assume that individual-level decision-making processes regarding fertility, marriage, and migration are shaped by neighborhood characteristics, and that neighborhoods that are close together (spatially) are more strongly linked than those that are more distant (for example, people are likely to build new households near their old neighborhoods). Furthermore, and consistent with empirical observations, we assume that the dominant land-use change in the settled area of the Valley is land conversion out of agriculture and into the built environment, and that new household formation is the major driving force behind this change. 


\section{Entities, state variables, and scales}

The Chitwan ABM represents the population of the Chitwan Valley using a multi-level structure mirroring that used in the CVFS (individuals, households, and neighborhoods, see Table 2) as well as the observed social context (electrification, existence of non-family organizations or NFOs), and land-use patterns. The lowest-level agent is a "person" agent. The person agent represents a single individual person from the CVFS survey. The model is initialized with 8,245 person agents. Each person agent has a number of attributes assigned based on the survey data (see Table A1.1 for a complete list). Each person agent is in turn assigned to one of 1,522 households, by matching the household ID number of each individual in the CVFS survey to the appropriate household number in the survey. Each household has a set of attributes assigned from empirical data (Table A1.2). Household agents are assigned to one of 151 neighborhoods, by linking household and neighborhood ID numbers from the CVFS survey. Neighborhoods, in turn, have a set of attributes (Table A1.3), including land use within each neighborhood.

Agricultural land is the predominant land use category within the cleared area of the study site. As of 1996, when the first CVFS mapping was conducted agricultural land occupied greater than $80 \%$ of the total non-forested land area. The CVFS collected land use data at three points in time (1996, 2000, and 2007) at the neighborhood-level. Each neighborhood was mapped by hand, with compasses and tape measures. The original survey mapped 18 different classes - for simplicity, and consistency with prior analyses (such as Yabiku 2006; Axinn and Ghimire 2007; Ghimire and Hoelter 2007), we collapse these 18 classes into 5 classes: agricultural vegetation, non-agricultural vegetation, private buildings, public buildings, and other (canals, ponds, rivers, silted land, and undeveloped land). 
Land use data was collected at the neighborhood-level through the CVFS - individual land parcels are not connected to individual households (as no unique IDs exist in the mapping data to match a household plot with its owner). The ABM tracks land use at the neighborhoodlevel, as the total land area within each class. Summary statistics on LULC within the CVFS sample neighborhoods are given in Table 1. Land use within the model itself is therefore stored as point data - land areas within each category, associated with a particular neighborhood.

The model runs with a monthly time step, beginning in January 1997 (the first month of the CVFS household registry data collection), and ending in December, 2050. A monthly time step was chosen in order to match the available data from the CVFS, while minimizing computational complexity (a smaller time step would significantly increase the computational requirements for running the model).

\section{Process overview and scheduling}

As seen in Figure A1.1, the Chitwan ABM runs with a monthly time step, and a series of submodels run in succession at each time step. Each submodel is briefly discussed here; see the Submodels subsection of the Details section for full details on each submodel. Each time step begins with the fertility submodel, which handles women's first children after marriage, and then handles subsequent births to women who have already had their first child. The mortality submodel runs next. The marriage submodel follows, and then the migration submodel which allows in and out-migration at the individual and household levels. The last submodels to run are the divorce submodel and the education submodel. Landscape change due to new household formation is modeled in both the marriage and migration submodels (see these subsections for details). 


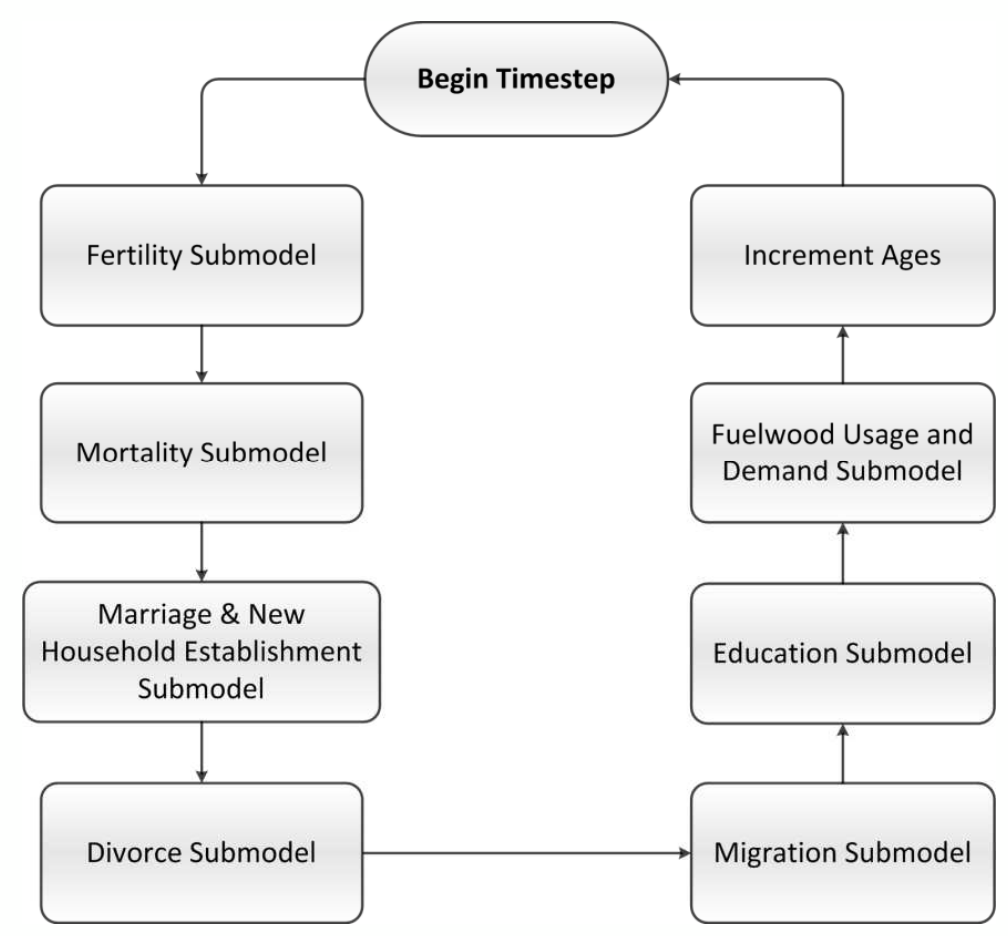

Figure A1.1: Process scheduling in the Chitwan ABM.

\section{DESIGN CONCEPTS}

In this section, we outline the key design concepts behind the Chitwan ABM, under the eleven major subheadings of the ODD protocol.

\section{Basic principles}

The Chitwan ABM draws on theory from the literature on the drivers of land-use and land-cover change, and from the sociological literature on the key determinants of demographic change. Existing work has shown the influence of land-use change (such as the prevalence of agriculture in an individual's neighborhood) on human behaviors including fertility, migration, and marriage. Drawing on this body of evidence, the Chitwan ABM uses separate submodels to model demographic and land-use change, allowing for reciprocal causation, whereby changes in land use can influence human behaviors, which, in turn, determine land use patterns. 


\section{Emergence}

Population dynamics and land-use change emerge based on the lower-level interactions and decisions of person and household agents. These decisions are governed by the process models build into the Chitwan ABM (see Submodels subsection of Details section).

\section{Adaptation}

Adaptation is not modeled directly in the present version of the Chitwan ABM. Though agents responses vary with environmental and demographic conditions, the models representing agent responses are fixed (the coefficients in the marriage model, for example, are fixed over the course of a model run).

\section{Objectives}

Agents do not seek to maximize "success" or the probability of a particular objective, but are instead modeled as autonomous agents encountering a number of decision-making points (marriage, education, migration, etc.). At each decision point, agents make decisions in accordance with the observed data, with a set of stochastic techniques (empirically derived probability distributions, regression models, heuristic models, etc.) used to model the decision making process.

\section{Learning}

Learning is not represented in the Chitwan $\mathrm{ABM}$ - the rules agents use to make decisions to not change over time. Agent's responses evolve over time based on changing demographic and environmental conditions; however, the decision rules and stochastic models are fixed.

\section{Prediction}

Agents in the Chitwan ABM do not use prediction models in their decision making.

\section{Sensing}


All person agents are assumed to know their own demographic and socioeconomic characteristics. Each person agent is also aware of the characteristics of their household and neighborhood, including land use in their local area. This information informs person agent's decisions. Global characteristics (total population, total land use) cannot be observed by the agents in the model.

\section{Interaction}

Agents interact with each other (marriage, divorce, and fertility) and with their environment (through new household establishment). The primary interaction between agents is marriage. In the marriage submodel, two eligible person agents may marry and may establish a new household with probability dependent on the state variables associated with each person, and on the coefficients of the marriage timing model and the household fission rate.

\section{Stochasticity}

Stochasticity plays a large role in the Chitwan ABM. Every submodel discussed in the Submodels subsection of the Details section includes a stochastic component. See this subsection for additional details on stochasticity in the Chitwan ABM.

\section{Collectives}

Two types of collectives exist in the Chitwan ABM: neighborhood agents and household agents. Neighborhood agents are composed of household agents, and household agents are composed of person agents. Both neighborhood and household agents also possess their own unique, higher-level state variables beyond those derived from their member households (they could be considered 'imposed' collectives as they are forced to exist by the definitions of the modelers).

\section{Observation}


Our primary result of interest for this paper is how feedbacks between natural and human systems affect spatial and temporal patterns of land use in the Chitwan Valley, and spatial and temporal patterns in human actions (marriage and first-births). As these phenomena are related in a complex manner, with feedbacks between human decisions and environmental change, the spatial patterns resulting from changes in first birth timing and marriage timing cannot be easily predicted. In order to observe the impact of feedbacks between first birth timing and land use and feedbacks between marriage timing and land use, we observe a set of model outcomes: first birth times, marriage ages, land use, and total population. Other outcomes, including household size, fuelwood usage, migration patterns, birth rates, mortality rates, and spatial patterns of demographic change can also be monitored, but are not considered for this paper.

\section{DETAILS}

Following the ODD description framework, in this section, we describe the details of model initialization, input data used to model exogenous processes (not applicable to the Chitwan ABM), and provide a detailed description of the submodels included in the ABM.

\section{Initialization}

The Chitwan ABM is initialized using household registry and survey data from the CVFS survey. The number of agents of each type follows the distribution of the CVFS data (see Table 2). There are four different types of agents (persons, households, neighborhoods, and regions), with the population of each type of agent determined by the number of respondents in the CVFS survey data. The respondents from the CVFS survey are represented in the model using a one-toone mapping, in which each agent in the model represents a single person, household, or neighborhood from the CVFS sample. There is only one region agent, of which all neighborhoods are a member (regions agents are included in the model code for usage in later 
experiments).

\section{Input data}

Other than the initialization data mentioned above, no exogenous input data is used in the Chitwan ABM to "model processes that change over time" (Grimm et al. 2010, 2765).

\section{Submodels}

Marriage, fertility, mortality, migration, education, and land-use change are modeled based on relationships derived from existing empirical works, and from our analysis of time series data from the CVFS. The model is designed with flexibility in mind, to allow testing of different hypotheses regarding feedbacks between demographic change and land-use. A modular design allows switching between alternative sub-models and parameterizations so that users may pick the most appropriate process representations for a particular research question.

\section{Marriage}

The marriage sub-model uses regression results to parameterize the marriage process based on a number of covariates. Prior studies in Chitwan has shown that individuals within primarily agricultural neighborhoods marry sooner than those in primarily urban neighborhoods, even when controlling for other factors (Yabiku 2006a). To represent this in the model, the marriage sub-model uses regression coefficients derived from a discrete-time-hazard analysis predicting probability of marriage within a given month depending on a number of covariates (Table 3). The covariates included in the marriage timing model are chosen based on the work of Yabiku (2006a).

The regression model used in the Chitwan ABM is based on the work of Yabiku (2006a). The model is based on the discrete-time event history model published by Yabiku (Table 2, model 5, on page 456 of Yabiku 2006). The regression model was rerun for this paper based on 
the same modeling strategy and controls Yabiku used, in order to obtain the intercept for the regression equation, and the values of the monthly dummy variables included in the model to represent the baseline hazard (these parameters were estimated, but not published in Yabiku, 2006a). As different statistical software was used, the regression coefficients used here vary slightly from those in the original paper, though the significance and effect sizes for the coefficients generally agree.

In Table 3 the regression coefficients are converted to odds ratios (exponentiated regression coefficients) so that they can be more easily interpreted. A positive odds ratio on a covariate therefore means that an increase in the covariate will lead to a decrease in marriage age (by increasing the monthly probability of marriage). In each time step, the marriage sub-model calculates the monthly probability of marriage for each eligible individual based on the values of these covariates during that time step.

Following the work of Yabiku (2006a), the marriage timing regression model includes the $\log$ of agricultural vegetation to be consistent with theoretical expectations of the feedback of land-use change on marriage timing. The log scale represents, for example, the expectation that the transition from $10 \%$ to $20 \%$ agriculture (a $10 \%$ change) would be expected to have more of an effect on individuals than the transition from, for example $80 \%$ to $90 \%$ agriculture (again a $10 \%$ change). While the magnitude of both these changes is identical, the relative impact of a doubling of agricultural land use $(10 \%-20 \%)$ would represent a greater qualitative change in a neighborhood than going from $80 \%-90 \%$ agriculture.

To model the marriage process, at the beginning of each time step, a list is made of all unmarried individuals (both male and female). The marriage process in the Chitwan begins with the model first running through this list and checking if each person (male or female) has reached 
the minimum marriage age (15), and is below the maximum marriage age (35, both are empirically determined). For those meeting these requirements, the probability of marriage within that time step is calculated for each individual using whichever of the two marriage submodels has been chosen for the model run. Once this probability is calculated, a random number is drawn on the interval of $[0,1]$, and, if the number is less than or equal to the probability of marriage for that individual, the person is added to a list of individuals to be married in that time step. To model in-migration through marriage, individuals may marry an in-migrant with a probability of .1, as calculated from the 48 months of the CVFS household registry data.

Next, males and females within the list are paired up, subject to the requirement that all individuals marry within their own ethnic group. Marriage outside of one's ethnic group is exceedingly rare in the Chitwan Valley. The empirical data shows that spouses tend to be fairly close in age, with the man tending to be slightly older than the woman. To account for the expected age differential between spouses, we assign a probability of marriage for each potential spouse based on the age difference between the individuals (see Figure A1.2 for details).

\section{Fertility}


There are three parts to the fertility model in the Chitwan ABM. First is the determination of a woman's desired family size. Second, a submodel is used to model the first birth after marriage. Third, a separate process models all subsequent births, up until a woman's desired family size is reached (or until she is no longer married, or dies). These models are developed using empirical data from the CVFS household registry, which contains monthly records of live births for all individuals in the survey.

Desired family size is determined based on the desired family size reported in the CVFS survey data. For new agents born into the model, a desired family size is assigned to each woman at marriage based on the histogram of the empirically reported data (see Figure A1.3). While future work may take into account covariates associated with desired family size, this is not done at present.

First birth timing is modeled in a similar manner to marriage timing, by using the results of a regression model to predict the monthly probability of birth for each eligible woman for each time step. Following the results of Ghimire and Hoelter (2007) and Ghimire and Axinn

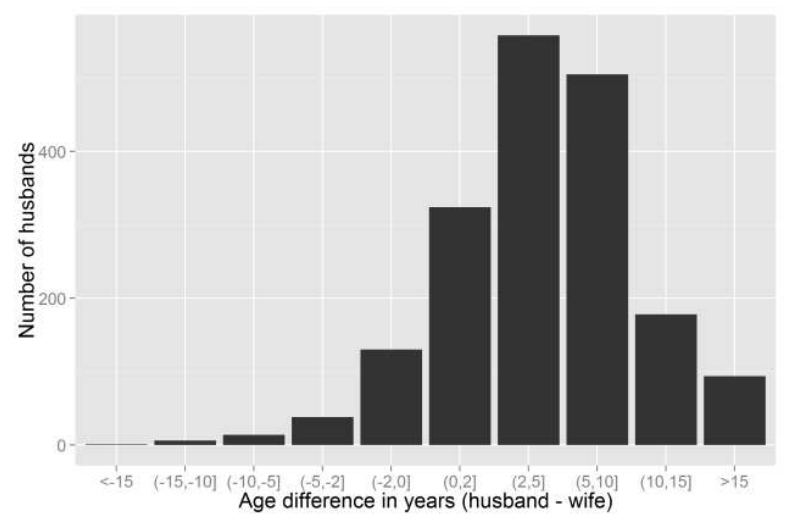

Figure A1.2: Empirically derived histogram of spouse age differences (in years) used to weight the probability of a given person agent marrying a particular potential spouse. 
(2010), we use discrete time event-history analysis to develop a regression model relating a series of covariates, including agricultural land use at the neighborhood level, to the monthly odds of a newly married woman having her first birth (Table 4). A positive odds ratio on a covariate therefore means that an increase in the covariate will lead to a decrease in first birth timing (by increasing the monthly probability of a first birth). The regression model used in the Chitwan ABM was rerun for this paper based on the modeling strategy and controls used in panel A, model 3 in Table 2 in Ghimire and Hoelter $(2007,309)$, in order to obtain the intercept for the regression equation (which was not published in Ghimire and Hoelter 2007). As different statistical software was used, the regression coefficients used here vary slightly from those in the original paper, though the significance and effect sizes for the coefficients generally agree.

At the beginning of each time step, a list is constructed of all married women who have not yet had their first birth, and who have a desired family size greater than zero. For each woman, a probability of first birth in that month is then calculated based on the values of all of

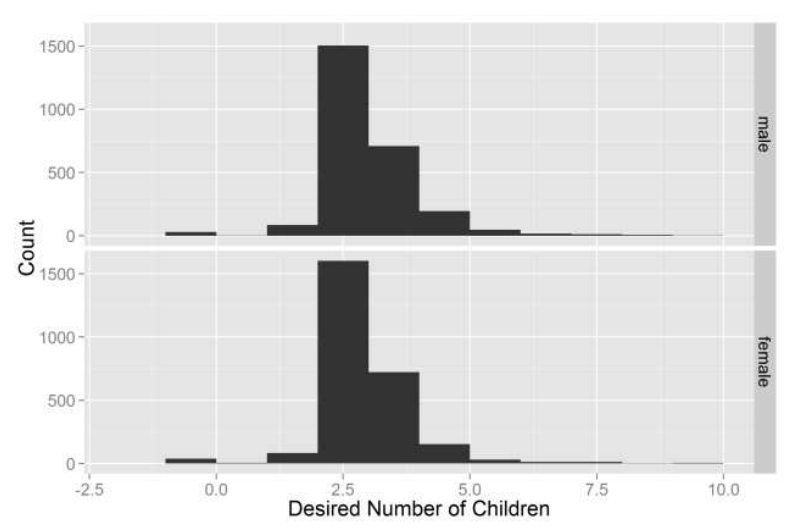

Figure A1.3: Desired number of children, plotted for male and female respondents, based on data from the CVFS. 


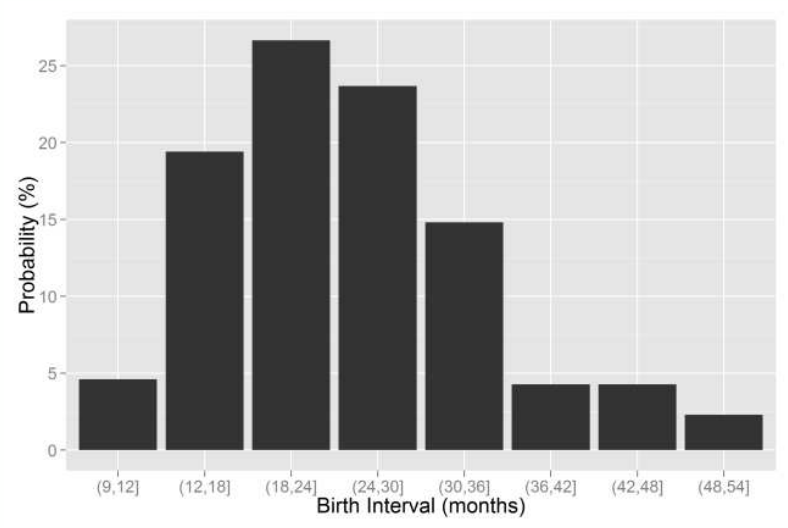

Figure A1.4: Time between births, plotted from survey data from the CVFS.

the model covariates for that month. A random number is drawn, and if it is less than the woman's probability of first birth, she will give birth in that month.

Following the first birth, additional births occur with birth intervals that are chosen from the empirically observed histogram of birth intervals (Figure A1.4). The maximum total number of births per woman is limited by the woman's desired family size. Once a woman is either too old to give birth (defined as age 45) or has reached her desired number of children, she is excluded from the fertility submodel.

\section{Mortality}

We model mortality as a simple random process, with age and sex dependent mortality rates. We calculate mortality rates using the first 48 months of the CVFS household registry data, which records all deaths that occur within the CVFS sample. Probability of mortality is calculated independently for males and females over identical bins (age in years, inclusive on the high end) of: $0-3,3-6,6-12,12-20,20-40,40-60,60-80,80-90,90$ and above (Figure A1.5). When an individual dies, they are removed from the model, and their spouse (if any) may marry again, as they are returned to the pool of individuals eligible for marriage on the next time step. 


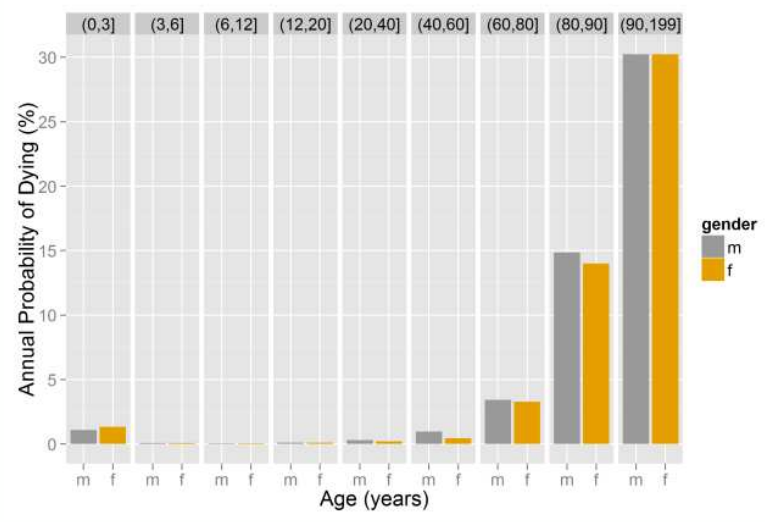

Figure A1.5: Mortality model from the Chitwan ABM. The annual probability of dying is empirically derived based on monthly data from the CVFS, and calculated independently for males and females in a number of different age groups.

\section{Migration}

We model individual and household-level out-migration in the Chitwan ABM. At the individual-level, a logistic regression model is used to calculate the probability of out-migration for any individual above the minimum age of migration (default of 15 years). The regression model (based on Massey, Axinn and Ghimire, 2010) takes into account a series of person-level, household-level, and community-level covariates to model the probability of an individual outmigration from the Chitwan Valley (Table A1.4) in a given month. We define individual migration following the "long distance migration" definition used by Massey, Axinn and Ghimire (2010) - as an individual "departure from the Chitwan Valley lasting at least a month".

Once a probability of migration is calculated for an individual, we draw a random number, and if that number is less than the calculated probability for that individual, then that individual out-migrates starting in that time step. The vast majority of migrants from Chitwan return within a relatively short period (as seen in Figure A1.6). To model this process, we include 


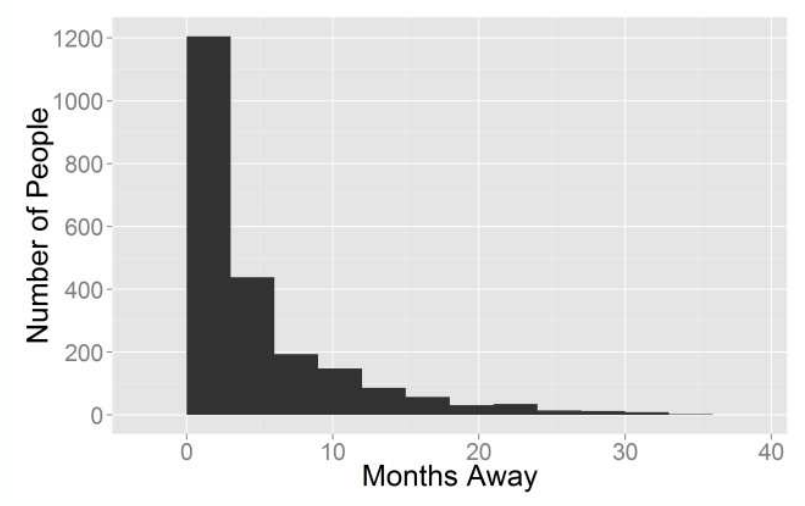

Figure A1.6: Empirically derived histogram of individual out-migration times (time from outmigration until return to Chitwan) in the Chitwan $\mathrm{ABM}$.

a second component in the migration model - a model of migration length. Once an individual becomes a migrant, an outmigration length is calculated. First, a random number is drawn to see if an out-migration is permanent. If the random number is less than the permanent out-migration probability, then that agent will be removed from the model, and the household will be tagged as having a permanent out-migrant member. If the person does not become a permanent out-migrant based on this calculation, a second random number is drawn, and is used to draw a random outmigration length from the empirically observed distribution of migration times (Figure A1.6). The out migrant agent is then added to a special group of person agents that, while not present in Chitwan, are still part of the model (their age increments every time step and they are still subject to the mortality submodel). If the person survives until a number of time steps equal to their outmigration length has passed, the person is then returned to their original household. Each household tracks a list of temporary out-migrants who are not currently present in the household, but who will be returning after an amount of time equal to their outmigration duration has passed. This list is used to ensure that a household is retained in the model even if it becomes entirely empty for a time due to its members making temporary migrations. 
Household level in- and out-migration is also modeled, whereby we allow an entire household to in- or out-migrate with probability specified by a fixed empirically derived parameter. Future work will explore variability in the demographic characteristics and environmental determinants of in- and out-migrating households, but for the present model we do not differentiate household-level in- or out-migration based on demographic or environmental state variables.

\section{Education}

Due to the importance of education as a predictor of demographic behavior, we model education endogenously in the Chitwan ABM. The education model is a two part process. First, using the results of an ordinal logistic regression (Table A1.5), a "final schooling level" (in years) is calculated for each person agent at age six. The schooling regression model takes into account gender, ethnicity, and access to non-family services (including schooling access) in each person's neighborhood. The final schooling level is the highest level of schooling that person may achieve in their lifetime (provided they live long enough to complete schooling, and do not permanently migrate outside of Chitwan (thus leaving the model). Also at age 6, the "schooling status" variable associated with each person is set to "in school", for each person whose calculated final schooling level is greater than zero. Every month, the model checks each person's schooling status. If the schooling status is "in school", and a person has not yet reached their final schooling level, a month is added to their schooling level, to simulate attending school during that month. Once a person reaches their final schooling level, their school status variable is set to "out of school", and the model will no longer increment their schooling level. 
When a new household is constructed in Chitwan, the land area it occupies is determined from a probability distribution of household land areas taken from the CVFS mapping data (Figure A1.7). To simulate land use conversion, an amount of land equal in area to the area of the new household is deducted from either the agricultural land use category (preferentially) or the non-agricultural vegetation land use category (if insufficient agricultural land exists) and is added to the private buildings category of the appropriate neighborhood. The household is preferentially built in the husband's parent's neighborhood. If there is not enough land available in that neighborhood for this to happen, the household will be located in the closest neighborhood to the husband's parents household that does have available land.

\section{CHANS characteristic features}

Coupled Human-Natural Systems (CHANS) have been noted to have characteristic features that can impact management policies: reciprocal effects and feedback loops, nonlinearity and thresholds, surprises, legacy effects and time lags, resilience, and heterogeneity (An et al. in press; Liu, Dietz, Carpenter, Alberti, et al. 2007). The primary feedbacks we focus on for this paper are between land use and the marriage timing and first birth timing submodels. As noted in

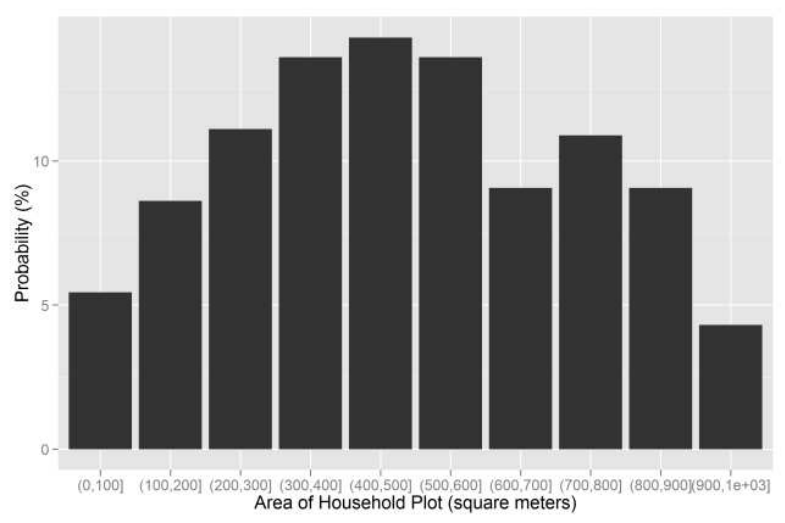

Figure A1.7: Empirically derived histogram of new household plot sizes (area in sq. m). 
the paper, feedbacks between land use and marriage timing and land use and first birth timing can lead to small, though statistically significant, differences in model outcomes in the Chitwan ABM.

Time lags are also are common in CHANS, and are observed in the Chitwan ABM. A prominent example is the lagged effect of changing first birth timing on agricultural land conversion. As seen in Figure 3, 2020 land use does not differ significantly between the calculated, half, and double effect scenarios in scenario set $\mathrm{C}$ (where the size of the first birth timing feedback is varied). The effects of changing first birth timing are only visible in the 2050 model results, as it takes some time for the effects of changed first birth timing to appear on the landscape due to the lag between additional births leading to an increase in birth leading to a subsequent increase in new household establishment as the "extra" children born due to shortened birth timing reach marriage age.

In Chitwan land-use change is resilient to moderate changes in fertility or marriage rates that affect the population balance. The primary determining factor behind land-use change that is represented in the model is new household establishment. This process is largely a legacy effect of past demographics - due to past high fertility rates, there was a large youth bulge in Chitwan in 1996. As this population ages and begins to establish new households, the effect is land transition out of agriculture. While large sudden shocks (substantial in/out-migration following a crisis for example) could affect land-use change temporarily, it does not affect this general dynamic. Heterogeneity of model outcomes is also a feature if the Chitwan ABM. Ethnic variation in marriage rates and fertility preferences, and spatial variation in non-family service access all influence the patterns we observe in the outcomes of the Chitwan model.

\section{Verification and validation}


Validation of the results of agent-based models is often difficult (Brown et al. 2005). To verify our results, we follow the process described in An et al. 2005. First, we conduct a progressive debugging and testing of the model, to catch errors in the model code. The model includes simplified versions of the key submodels (a first birth timing model that is purely a histogram for example, for example). The results of model runs with these simplified submodels are compared to runs with the more complex submodels. Large differences between these model runs indicate errors may exist in the model code. Second, the model is verified using extreme value tests and extreme combination tests, to test that the model responds as expected to extreme values of model parameters. Third, we conduct a sensitivity analysis, testing the sensitivity of model outcomes to small changes in key model parameters. Lastly, while the availability of a time series of social data from the CVFS facilitates model parameterization, it also allows validation of model outcomes as we can compare simulated outcomes to observed data. A subset of the monthly CVFS data (data from the 1996-2002 surveys) was used to calibrate the model, while leaving data from later surveys (2002-2008) for validation (evaluation of the extent to which the model results reflect the observed data). 


\section{REFERENCES}

An, L., M. A. Linderman, J. Qi, A. Shortridge, and J. Liu. 2005. Exploring complexity in a human environment system: An agent-based spatial model for multidisciplinary and multiscale integration. Annals of the Association of American Geographers 95 (1):54-79.

An, L., A. Zvoleff, J. Liu, and W. G. Axinn. in press. Agent based modeling in coupled human and natural systems (CHANS): Lessons from a comparative analysis. Annals of the Association of American Geographers.

Axinn, W. G., and D. J. Ghimire. 2007. Social organization, population, and land use. University of Michigan: Population Studies Center.

Axinn, W. G., A. Thornton, J. S. Barber, S. A. Murphy, D. J. Ghimire, T. Fricke, S. Matthews, D. R. Dangol, L. D. Pearce, A. Biddlecom, S. Shrehtha, and D. Massey. 2011. Chitwan Valley Family Study. University of Michigan, Population Studies Center and Survey Research Center.

Brown, D. G., S. Page, R. Riolo, M. Zellner, and W. Rand. 2005. Path dependence and the validation of agent-based spatial models of land use. International Journal of Geographical Information Science 19 (2):153-174.

Ghimire, D. J., and W. G. Axinn. 2010. Community context, land use, and first birth. Rural Sociology 75 (3):478-513.

Ghimire, D. J., and L. F. Hoelter. 2007. Land use and first birth timing in an agricultural setting. Population \& Environment 28:289-320.

Grimm, V., U. Berger, F. Bastiansen, S. Eliassen, V. Ginot, J. Giske, J. Goss-Custard, T. Grand, S. K. Heinz, G. Huse, A. Huth, J. U. Jepsen, C. Jørgensen, W. M. Mooij, B. Müller, G. Pe'er, C. Piou, S. F. Railsback, A. M. Robbins, M. M. Robbins, E. Rossmanith, N. Rüger, E. Strand, S. Souissi, R. A. Stillman, R. Vabø, U. Visser, and D. L. DeAngelis. 2006. A standard protocol for describing individual-based and agent-based models. Ecological Modelling 198 (1-2):115-126.

Grimm, V., U. Berger, D. L. DeAngelis, J. G. Polhill, J. Giske, and S. F. Railsback. 2010. The ODD protocol: A review and first update. Ecological Modelling 221 (23):2760-2768.

Liu, J., T. Dietz, S. R. Carpenter, M. Alberti, C. Folke, E. F. Moran, A. N. Pell, P. Deadman, T. Kratz, J. Lubchenco, E. Ostrom, Z. Ouyang, W. Provencher, C. L. Redman, S. H. Schneider, and W. W. Taylor. 2007. Complexity of coupled human and natural systems. Science 317 (5844):1513-1516.

Massey, D., W. G. Axinn, and D. J. Ghimire. 2010. Environmental change and out-migration: Evidence from Nepal. Population and Environment.

Yabiku, S. T. 2006. Land use and marriage timing in Nepal. Population \& Environment 27 (5):445-461. 


\section{TABLES}

\begin{tabular}{|c|c|c|}
\hline Attribute & Possible Values & Initial Value \\
\hline Person ID & $001001001-151999999$ & Unique value assigned at birth \\
\hline Age (months) & 0 - age at death & 0 \\
\hline Gender & Male, female & Random, either male or female \\
\hline Ethnicity & $\begin{array}{c}\text { High-caste Hindu, Low-caste Hindu, } \\
\text { Newar, Hill Tibeto-Burmese, Terai } \\
\text { Tibeto-Burmese }\end{array}$ & Father's ethnicity \\
\hline Mother ID & 001001001-151999999 & Derived from mother \\
\hline Father ID & 001001001-151999999 & Derived from father \\
\hline ID of household at birth & 001001-151999 & Derived from mother \\
\hline $\begin{array}{l}\text { ID of neighborhood at } \\
\text { birth }\end{array}$ & $001-151$ & Derived from mother \\
\hline Date of last migration & $1 / 1995-12 / 2049$ & None $^{\dagger}$ \\
\hline $\begin{array}{l}\text { Date of last birth } \\
\text { (women) }\end{array}$ & $1 / 1995-12 / 2049$ & None $^{\dagger}$ \\
\hline Spouse & $\begin{array}{c}\text { None, reference to spouse 'person' } \\
\text { instance }\end{array}$ & None $^{\dagger}$ \\
\hline \multicolumn{3}{|l|}{ Marriage time } \\
\hline Child list & List of children 'person' instances & None $^{\dagger}$ \\
\hline Ever work for pay & True, False & $\begin{array}{c}\text { Set to 'yes' with probability } \\
.205 \text { for females and } .450 \text { for } \\
\text { males }^{\ddagger}\end{array}$ \\
\hline \multicolumn{3}{|l|}{ Education: } \\
\hline Schooling status & $\begin{array}{l}\text { Undetermined, in school, out of } \\
\text { school }\end{array}$ & Undetermined \\
\hline Final schooling level & $0-15$ & None $^{\dagger}$ \\
\hline Years of schooling & $0-15$ & 0 \\
\hline \multicolumn{3}{|l|}{ Mother's characteristics: } \\
\hline Years of schooling & $0-15$ & Derived from mother \\
\hline Ever work for pay & Yes, No & Derived from mother \\
\hline Number of children & $0-10$ & Derived from mother \\
\hline \multicolumn{3}{|l|}{ Father's characteristics: } \\
\hline Years of schooling & $0-15$ & Derived from father \\
\hline Ever work for pay & Yes, No & Derived from father \\
\hline \multicolumn{3}{|c|}{ Attributes assigned only to female person agents: } \\
\hline $\begin{array}{l}\text { Desired number of } \\
\text { children }\end{array}$ & $0-10$ & Taken from CVFS data \\
\hline Time of last birth & $1 / 1997-12 / 2049$ & Reset after each birth \\
\hline
\end{tabular}

Table A1.1: Attributes of the 'person' agent type.

Note that the initial values listed here and in Table A1.2 are the values given to agents that are endogenously generated during a model run (for people, through birth or in-migration). The initial values of attributes for person agents present in 1997 at the beginning of the model are taken directly from the survey data. 'Parameters with initial values of 'None' are set equal to the 'None' value in the model code, and conditional statements are used in the model to handle cases where attributes are set to 'None' (for example, for the date of last migration, a value of 'None' would mean that no prior migration has occurred)., and for the education model, a final schooling level of 'None' would indicate the education submodel has not yet been run for that agent. $\ddagger$ From CVFS data 
Appendix 1: Overview, Design Concepts, and Details (ODD) of the Chitwan ABM

\begin{tabular}{ccc}
\hline \hline Attribute & Possible Values & Initial Value \\
\hline Household ID & $001001-151999$ & Unique value assigned at \\
household establishment \\
Own household plot & Yes, No & Set to 'yes' with probability \\
Own land & Yes, No & $.93^{\dagger}$ \\
& Set to 'yes' with probability \\
Rent out land & Yes, No & $.83^{\dagger}$ \\
Use any non-wood fuel & Yes, No & Set to 'yes' with probability \\
& & $.61^{\ddagger}$ \\
Time of last migration & $1 / 1995-1 / 2050$ & Set to 'yes' with probability \\
\hline
\end{tabular}

Table A1.2: Attributes of the 'household' agent type.

${ }^{\dagger}$ From CVFS data ${ }^{\ddagger}$ Axinn and Ghimire (2007) 
Appendix 1: Overview, Design Concepts, and Details (ODD) of the Chitwan ABM

\begin{tabular}{|c|c|c|}
\hline Attribute & Possible Values & Initial Value \\
\hline Neighborhood ID & $001-151$ & Taken from CVFS data \\
\hline $\mathrm{x}, \mathrm{y}$ coordinates & $\begin{array}{l}\text { UTM45N coordinates of } \\
\text { neighborhood }\end{array}$ & Taken from CVFS data \\
\hline Elevation (m) & $143-207$ & $\begin{array}{c}\text { Taken from } 90 \mathrm{~m} \mathrm{SRTM} \\
\text { DEM }\end{array}$ \\
\hline Electricity available & Yes, No & Taken from CVFS data \\
\hline Land area: agriculture (sq. m) & $0-280,915$ & Taken from CVFS data \\
\hline $\begin{array}{l}\text { Land area: non-agriculture (sq. } \\
\mathrm{m} \text { ) }\end{array}$ & $0-36,130$ & Taken from CVFS data \\
\hline $\begin{array}{c}\text { Land area: private buildings } \\
\text { (sq. m) }\end{array}$ & $253-20,386$ & Taken from CVFS data \\
\hline $\begin{array}{l}\text { Land area: public buildings (sq. } \\
\mathrm{m} \text { ) }\end{array}$ & $100-80,448$ & Taken from CVFS data \\
\hline Land area: other (sq. m) & $0-14,484$ & Taken from CVFS data \\
\hline Distance to urban center $(\mathrm{km})$ & $0-28$ & $\begin{array}{l}\text { Calculated from } \\
\text { coordinates }\end{array}$ \\
\hline $\begin{array}{l}\text { Distance to nearest school } \\
\text { (minutes on foot) }\end{array}$ & $0-30$ & Taken from CVFS data \\
\hline $\begin{array}{l}\text { Distance to nearest health post } \\
\text { (minutes on foot) }\end{array}$ & $0-90$ & Taken from CVFS data \\
\hline $\begin{array}{l}\text { Distance to nearest bus stop } \\
\text { (minutes on foot) }\end{array}$ & $0-75$ & Taken from CVFS data \\
\hline $\begin{array}{l}\text { Distance to nearest market } \\
\text { (minutes on foot) }\end{array}$ & $0-120$ & Taken from CVFS data \\
\hline $\begin{array}{c}\text { Distance to nearest employer } \\
\text { (minutes on foot) }\end{array}$ & $0-480$ & Taken from CVFS data \\
\hline
\end{tabular}

Table A1.3: Attributes of the 'neighborhood' agent type. 
Appendix 1: Overview, Design Concepts, and Details (ODD) of the Chitwan ABM

\begin{tabular}{|c|c|c|c|}
\hline & Odds Ratio & $\mathrm{p}$ & Sig. \\
\hline Enrolled in school & 0.82 & 0.062 & r \\
\hline Years of schooling & 1.075 & $<.001$ & $* * *$ \\
\hline Female & 0.624 & $<.001$ & $* * *$ \\
\hline \multicolumn{4}{|l|}{ Physical capital } \\
\hline Market access & 1.026 & 0.516 & \\
\hline Farmland & 0.93 & 0.528 & \\
\hline \multicolumn{4}{|l|}{ Age } \\
\hline $15-25$ & 2.797 & $<.001$ & $* * *$ \\
\hline $25-35$ & 1.544 & 0.021 & $*$ \\
\hline $35-45$ & 0.94 & 0.751 & \\
\hline $45-55$ & 1.05 & 0.807 & \\
\hline \multicolumn{4}{|l|}{ Ethnicity $^{\dagger}$} \\
\hline Low-Caste Hindu & 1.109 & 0.477 & \\
\hline Hill Tibeto-Burmese & 1.222 & 0.083 & . \\
\hline Newar & 0.854 & 0.339 & \\
\hline Terai Tibeto-Burmese & 0.617 & $<.001$ & $* * *$ \\
\hline \multicolumn{4}{|l|}{ Duration } \\
\hline Month & -0.565 & $<.001$ & $* * *$ \\
\hline Month squared & 0.116 & 0.05 & . \\
\hline Intercept & 0.007 & $<.001$ & $* * *$ \\
\hline
\end{tabular}

Table A1.4: Model of local-distant migration (following the work of Massey et al. 2010).

Odds-ratios are from a discrete time event history analysis predicting monthly hazard of making a move outside of the Chitwan Valley. Two sided $\mathrm{P}$-values. Significance is coded as: · for $\mathrm{P}<0.1$, * for $\mathrm{P}<.05, * *$ for $\mathrm{P}<0.01, * * *$ for $\mathrm{P}<0.001$. ${ }^{\dagger}$ The odds-ratios for ethnicity are relative to Upper-caste Hindus. ${ }^{\star}$ For month and month-squared coefficients are listed rather than odds ratios as for these two covariates odds ratios are not directly interpretable (e.g. month cannot be held constant without varying month-squared). 


\begin{tabular}{|c|c|c|c|}
\hline & Odds Ratio & $\mathrm{p}$ & Sig. \\
\hline \multicolumn{4}{|l|}{ Neighborhood level } \\
\hline Avg. years non-family services (15 min. $\mathrm{ft}$.) & 1.1 & $<0.001$ & $* * *$ \\
\hline \multicolumn{4}{|l|}{ Individual level } \\
\hline Female & 0.1 & $<0.001$ & $* * *$ \\
\hline \multicolumn{4}{|l|}{ Ethnicity } \\
\hline Low-Caste Hindu & 0.1 & $<0.001$ & $* * *$ \\
\hline Hill Tibeto-Burmese & 0.2 & $<0.001$ & $* * *$ \\
\hline Newar & 1.0 & 1 & \\
\hline Terai Tibeto-Burmese & 0.1 & $<0.001$ & $* * *$ \\
\hline \multicolumn{4}{|l|}{ Intercepts } \\
\hline Years schooling greater than 0 , less than 4 & 8.0 & $<0.001$ & $* * *$ \\
\hline Years schooling greater than 4 , less than 8 & 3.9 & $<0.001$ & $* * *$ \\
\hline Years schooling greater than 8, less than 11 & 1.00 & 0.900 & \\
\hline Years schooling greater than 11 & 0.2 & $<0.001$ & $* * *$ \\
\hline Avg. years non-family services (15 min. ft.) & 1.1 & $<0.001$ & $* * *$ \\
\hline
\end{tabular}

\section{Table A1.5: Education model used in the Chitwan ABM.}

The model is derived from analysis of a sample of CVFS data including all individuals aged 25-30 in 1996. Oddsratios are from an ordinal logistic regression predicting education level as $0,0-4,4-8,4-11$ or $>11$ years. P-values are two-sided. Significance is coded as: - for $\mathrm{P}<0.1, *$ for $\mathrm{P}<.05, * *$ for $\mathrm{P}<0.01, * * *$ for $\mathrm{P}<0.001 . \mathrm{n}=715$, pseudo $\mathrm{R}^{2}=.435$. ${ }^{\dagger}$ The odds-ratios for ethnicity are relative to Upper-caste Hindus. 


\section{Appendix 2.}

Note on time scales of data used in Chitwan ABM parameterization.

This brief note discusses the potential effects on Chitwan ABM model results of the range of time scales of the key datasets used in parameterizing the Chitwan ABM. The Chitwan ABM is parameterized primarily using datasets from the Chitwan Valley Family Study (CVFS, Axinn et al. 2011). The three datasets used from the CVFS are the Household Registry, Household Agriculture and Consumption, and Land Use Mapping surveys (Table A2.1). While the Household Registry is collected monthly, the Household Agriculture and Consumption and Land Use Mapping surveys are collected approximately every 5 years. Therefore, the timing of vital events (recorded in the household registry) is known with higher precision than the timing of changes in household-level variables and land use.

Given the difference in the temporal scales of data collection, vital events cannot be tied precisely in time to land use changes, or vice versa. If, for example, a couple marries and (after some time lag) moves out of their parental home and establishes a new household following marriage, the data of the marriage will be known within a month, as it is tracked in the monthly household registry dataset. The timing of any accompanying land use change, however, will be known only within a 1-5 year timeframe (depending on the date of the next land use data collection).

Rather than limit the Chitwan ABM to an annual or longer timestep (in accordance with the temporal resolution of the land use data), we have chosen to use a monthly timestep. This allow the model to represent more precisely the timing of demographic processes that occur at a faster rate than land use change (such as fertility, and migration), and for which we have available monthly data. The temporal resolution of the CVFS dataset in unique in this respect - 
monthly, longitudinal demographic datasets are relatively uncommon. Given the available data in Chitwan is possible to investigate the effects on model outcomes of parameterizing the model with monthly versus annual or semi-decadal demographic datasets, by degrading the monthly data from the CVFS to a lower temporal resolution, re-parameterizing the model using the degraded data, and comparing the outcomes from different model parameterizations. Land use changes could potentially be examined at a higher temporal resolution (though lower spatial resolution) through use of multi-temporal imagery from sensors such as Landsat or the Moderate Resolution Imaging Spectroradiometer (MODIS). Though beyond the scope of the present paper, this is one area to examine in future work, with important implications for models of land use change in which multiple datasets are used with different temporal timescales. 


\section{REFERENCES}

Axinn, W. G., A. Thornton, J. S. Barber, S. A. Murphy, D. J. Ghimire, T. Fricke, S. Matthews, D. R. Dangol, L. D. Pearce, A. Biddlecom, S. Shrehtha, and D. Massey. 2011. Chitwan Valley Family Study. University of Michigan, Population Studies Center and Survey Research Center. 


\section{TABLES}

\begin{tabular}{ccc}
\hline \hline Data Type & Sampling Unit & Notes \\
\hline Household Registry & Individual & Longitudinal, collected monthly \\
$\begin{array}{c}\text { Household Agriculture and } \\
\text { Consumption Surveys }\end{array}$ & Household & Longitudinal, collected every 4-7 years \\
Land Use Mapping & Neighborhood & Longitudinal, collected every 5 years \\
\hline
\end{tabular}

Table A2.1: Time scales of data collection for the three key CVFS datasets used to parameterize the Chitwan ABM. 